\title{
Shame in Two Cultures: Implications for Evolutionary Approaches
}

\author{
DANIEL M.T. FESSLER*
}

\begin{abstract}
Cross-cultural comparisons can a) illuminate the manner in which cultures differentially highlight, ignore, and group various facets of emotional experience, and b) shed light on our evolved species-typical emotional architecture. In many societies, concern with shame is one of the principal factors regulating social behavior. Three studies conducted in Bengkulu (Indonesia) and California explored the nature and experience of shame in two disparate cultures. Study 1, perceived term use frequency, indicated that shame is more prominent in Bengkulu, a collectivistic culture, than in California, an individualistic culture. Study 2, comparing naturally occurring shame events (Bengkulu) with reports thereof (California), revealed that shame is associated with guilt-like accounts in California but not in Bengkulu, and subordinance events in Bengkulu but not in California; published reports suggest that the latter pattern is prominent worldwide. Study 3 mapped the semantic domain of shame using a synonym task; again, guilt was prominent in California, subordinance in Bengkulu. Because shame is overshadowed by guilt in individualistic cultures, and because these cultures downplay aversive emotions associated with subordinance, a fuller understanding of shame is best arrived at through the study of collectivistic cultures such as Bengkulu. After reviewing evolutionary theories on the origins and functions of shame, I evaluate these perspectives in light of facets of this emotion evident in Bengkulu and elsewhere. The available data are consistent with the proposition that shame evolved from a rank-related emotion and, while motivating prestige competition, cooperation, and conformity, nevertheless continues to play this role in contemporary humans.
\end{abstract}

\section{KEYWORDS}

Shame, guilt, subordinance, conformity, evolution, Indonesia.

*Center for Behavior, Evolution, and Culture \& Department of Anthropology, UCLA, Los Angeles, CA 90095-1553, U.S.A. E-mail: dfessler@anthro.ucla.edu 


\section{Introduction}

Conformity to complex local norms is a defining feature of our species. Although exogenous factors such as the existence of punishment (cf. Boyd \& Richerson, 1992) can play an important role in norm conformity, much conformist behavior appears to be endogenously motivated. Emotions likely play an important role in this regard, foremost among which is probably shame. The cross-cultural investigation of shame can therefore simultaneously achieve multiple aims relevant to the study of cognition and culture. First, cross-cultural comparisons can shed light on the manner in which culture shapes both thought and experience in the domain of emotion. Second, cross-cultural studies of shame can illuminate the process whereby a key factor motivating human conformism evolved.

Anthropologists (e.g., Benedict, 1946; Mead, 1937) were among the first to systematically explore shame. Although such research persisted for some time (e.g., Creighton, 1990; Fajans, 1983; Lebra, 1983), with the fading of the culture-and-personality paradigm in anthropology, the topic gradually fell out of favor. Over the last two decades psychologists have refocused the spotlight on shame, making important strides in understanding this emotion. Consistent with a larger trend in the exploration of emotions (Cosmides \& Tooby, 2000; Frank, 1988; Johnston, 1999; Nesse, 1990; Öehman \& Mineka, 2001), some of the most compelling contemporary psychological approaches to shame adopt an evolutionary perspective. Evolutionary explanations rest on the identification of panhuman psychological features. Both the study of human universals and the exploration of human evolution are of central concern to anthropology, hence anthropologists are well positioned to contribute to the current renaissance in the study of shame.

\section{The Role of Cross-Cultural Research in the Study of Shame}

For two reasons, shame is best investigated cross-culturally. First, evolutionary accounts of shame are premised on the supposition that the capacity to experience this emotion is panhuman. While a body of research employing university students (Al-ansari, 2000; Fontaine, Poortinga, Setiadi \& Markam, 2002; Scherer, 1997; Scherer \& Wallbott, 1994) supports this premise, such work is limited in that it relies on i) methods that are removed from daily life, and ii) participants who have had considerable 
exposure to Western culture. ${ }^{1}$ Additional evidence of shame's nature and universality can therefore bolster evolutionary accounts. The second factor motivating cross-cultural research on shame stems from the complex nature of the relationship between culture and emotion.

Cultural constructivists (e.g., Kitayama, Markus \& Matsumoto, 1995; Lutz, 1988; Lutz \& White, 1986; Rosaldo, 1984; Wierzbicka, 1986, 1992) argue that the experience of emotions is fundamentally determined by the culturally constituted nature of subjective reality. However, noting that it is not difficult to discern familiar emotions in ethnographic accounts of ostensibly exotic cultures, some evolutionary psychologists dismiss this position as much ado about nothing. Such a move entails substantial liabilities, for it results in a failure to consider the impact that culture may have on both the participant's and the investigator's views of the emotions at issue.

Culture can be usefully seen as elaborating on or ignoring various human propensities. These polar processes, termed hypercognizing and hypocognizing (Levy, 1973), likely play a key role in generating the crosscultural variation focused upon by cultural constructivists (see also Frijda \& Mesquita, 1994). Of importance for the evolutionist, the ubiquity of cultural hyper- and hypocognizing means that no single population can provide a direct and complete avenue for the exploration of panhuman emotional architecture - differential cultural exaggerating or ignoring of various features of emotional experience is such that relying on a single society (or set of related societies) limits our ability to discern the full outline of the species-typical trait.

\section{Exploring Shame Across Two Cultures}

To both examine culture's impact on shame and obtain a more complete portrait of this emotion, I sought to explore shame in two markedly disparate cultures. Published reports (Sutlive, 1972; Swift, 1965) and my

\footnotetext{
${ }^{1}$ A large body of research explores the experience of shame in Japan (cf. Benedict, 1946; Crystal et al., 2001; Lebra, 1983; Miyake \& Yamazaki, 1995). While interesting differences are evident between Japan and the West in this regard, in light of the extensive exposure to Western culture typical of most contemporary Japanese, Japan is not an optimal initial point of comparison for investigations that aim to illuminate aspects of shame that are difficult to discern from a Western perspective (see text).
} 
own previous research in the region indicated that shame-like emotions play a prominent role in the daily lives of the Malay peoples of Southeast Asia. As part of a larger project investigating the role of emotions in the regulation of social behavior, I therefore selected a relatively traditional Malay fishing village located in the Indonesian province of Bengkulu on the southwest coast of Sumatra (see Fessler, 1995 for details). Research involved intensive prolonged participant observation; for 32 months I lived in the center of the village and participated in nearly all aspects of daily life. Members of the community understood my goal to be documenting their way of life; they were not aware of my interest in emotions prior to the initiation of structured research tasks during the the 24th month of fieldwork and, even after this point, they did not know that shame constituted a principal focus of the investigation. Conversations, interviews, and structured tasks were all conducted in the Kota Bengkulu dialect of the Malay language.

Urban Southern California is both literally and figuratively on the opposite side of the globe from Bengkulu. In many ways, the educated middle- and upper-middle-class inhabitants of this region epitomize citizens of a modern, highly fluid, industrialized nation-state. Southern California thus provided a useful point of contrast to Bengkulu.

In developing methods to investigate the experience of shame in disparate cultures, I sought a compromise between the anthropologist's emphasis on ecological validity and the psychologist's emphasis on quantifiability and comparability. Despite the attendant costs, much of the crosscultural work on shame to date has placed priority on the latter (e.g., Al-ansari, 2000; Fontaine, Poortinga, Setiadi \& Markam, 2002; Scherer, 1997; Scherer \& Wallbott, 1994). I therefore attempted to devise methods which, while producing quantified results that minimize the need for discursive interpretation or rich ethnographic background, nevertheless incorporate local systems of meaning. In each of the studies described below, rather than selecting concepts or terms of a priori interest and imposing them on participants, I instead developed test materials by working within the culture at issue. Though this procedure decreases strict comparability across cultures, it enhances the likelihood that the concepts in question will best reflect participants' own ethnopsychologies and experiences. 


\section{Study 1 - The Prominence of Shame in Everyday Life}

Bengkulu was selected as a study site on the basis of the impression that concern with malu, an emotion term reasonably translated as 'shame' (Echols, Shadily, Collins \& Wolff, 1989; Fontaine et al., 2002; Goddard, 1996), is an important part of life in this region. Anthropologists have long claimed that shame is less important in the West than in many cultures (Benedict, 1946; Mead, 1937), a position that has been revived somewhat by work on individualism/collectivism (Hofstede, 1991). Since the goal of the present research was to use cross-cultural comparisons to gain a more complete understanding of shame, it was important to first establish the salience of shame in the two cultures at issue in order to provide a context for the interpretation of other results. Reasoning that individuals' perceptions of the frequency with which various emotion terms are used in daily discourse should roughly reflect each emotion's prominence in social interactions, cultural schemas, and experience, I devised a card ordering task to measure such perceptions. Note that the issue here concerns not only how frequently the given emotion is experienced, but also how much attention is dedicated to it. Some emotions may be extensively discussed yet rarely experienced, a configuration likely to characterize both pre- and proscribed emotions, as gossip often concerns the potentially laudatory or disgraceful attributes and motives of others. However, the converse is unlikely to be true - emotions for which a lexical label exists that are frequently experienced are unlikely to be rarely discussed, simply because much discourse consists of recounting recent experiences. Accordingly, in general, terms that are perceived to be used frequently can reasonably be assumed to refer either to rare-but-prominent experiences or to common experiences, whereas terms that are perceived to be used rarely can be presumed to refer to experiences that are neither prominent nor common.

\section{The Perceived Frequency of Malu in Bengkulu Discourse}

Previous work on another topic indicated that Bengkulu participants could comfortably manage card ordering tasks involving approximately 50 items. A list of 52 terms considered common emotions (perasoan 'ati in the Kota Bengkulu dialect of Malay; cf. Shaver, Murdaya \& Fraley, 2001) was therefore drawn up through informal interviews conducted with five 
women and six men. ${ }^{2}$ Each term was printed on a small card. The majority of the mature literate individuals in the village $(\mathrm{n}=80$ : 19 adult women, 20 adolescent/young women, 22 adult men, and 19 adolescent/young men) each received a set of 52 preshuffled cards and were asked to take them home, spread them out on the floor, arrange them in order of the frequency with which they were employed in discourse by people in the village, then restack them in that order with the most frequent term on the top and the least frequent on the bottom. No contexts, uses, or connotations of the terms were specified - participants were simply told to order the cards with regard to the frequency with which the words themselves were spoken. Participants were asked not to seek assistance from others, and were assured that there were no correct or incorrect answers. Participants received tickets for a lottery with a cash prize equivalent to five day's wages; a single drawing involving tickets from multiple tasks was held at the conclusion of the fieldwork period in conjunction with a celebratory festival open to all members of the village.

\section{The Perceived Frequency of Shame in Californian Discourse}

In California, a focus group composed of eight native speakers of English (four women and four men) drew up a list of what they considered to be 52 of the most common English emotion terms; the focus group was told to concentrate only on frequency, and was given latitude as regards tense, form, etc. The terms were written on cards and shuffled. Participants were told to take the cards home, spread them out on a table, and then arrange the terms in order of the frequency with which they were used in daily discourse by Southern Californians with whom the participant often

\footnotetext{
${ }^{2}$ At the time of research, the term emosi, from the English term 'emotion,' was gaining currency elsewhere in Indonesia. In Bengkulu this word had taken on a more specific meaning, namely 'angry, upset.' The list of terms contains four items ('honest,' 'kind,' 'polite,' and 'wise') that English speakers consider character terms rather than emotions (the tendency for Malay speakers to introduce character terms when discussing emotions, a phenomenon that also occurred during the synonym task, is evident in the work of other investigators [Heider, 1991; Shaver et al., 2001]). 40 of the remaining terms are either the same in Indonesian or have Indonesian cognates; 31 of these appear in Shaver et al.'s list of prototypical Indonesian emotion terms (Shaver et al., 2001). Unfortunately, a number of terms of interest (bangga, pride; cemburu, jealousy; bersalah, see note 10) on Shaver et al.'s list were not included in the Bengkulu list.
} 
interacted; once again, no contexts, uses, or connotations were specified, and participants were simply told to order the terms with regard to the frequency with which the words themselves were spoken. Participants were asked not to seek assistance from others or to consult reference materials, and were assured that there were no correct or incorrect answers. Participants were also told that, if a term had multiple meanings, they were to evaluate its frequency only with regard to that meaning which refers to an emotion. ${ }^{3}$ Four undergraduate research assistants solicited participation from middle- and upper-middle class (crudely determined on the basis of place of residence and lifestyle) friends, family members, and associates who were born in California and spoke English as a native language; as in the other Californian studies reported here, the identities of the participants were not recorded, and no compensation was offered. Thirty-seven women (age 18-49, $\mathrm{M}=23.9$ ) and 38 men (age 18-80, $\mathrm{M}=25.6$ ) participated.

Results from Bengkulu and California were compiled by assigning an ordinal number to each term in a participant's card stack, summing the values across participants for each term, calculating the mean value per term, and arranging the terms accordingly. Table 1 displays the results. ${ }^{4}$

\section{Discussion}

In Bengkulu, participants were recruited from a single village, the vast majority of the members of which were born and raised in that very community. In contrast, in California, participants were recruited from a large urban population containing substantial ethnic diversity, with only loosely-defined socioeconomic status, native English language, and rearing in the (huge) region of Southern California serving as common denominators. The potential thus existed for substantially greater cultural heterogeneity in the Californian sample, a pattern that might have called into question the comparability of the two bodies of data. It is therefore reassuring to note that, to the extent that the standard deviations of the frequency rankings can be taken as indices of cultural consensus, the Californian sample does not display greater cultural heterogeneity than

\footnotetext{
${ }^{3}$ This problem does not arise in the Kota Bengkulu dialect of Malay for the terms employed.

${ }^{4}$ All Bengkulu-to-English translations are by the author.
} 


\section{Table 1}

Perceived relative frequency of use of 52 Bengkulu emotion terms and 52 Californian English emotion terms. Each term is followed by its mean rank (out of a possible 52) and, in brackets, standard deviation. Bengkulu $n=80$; California $n=75$.

\section{Bengkulu Malay}

1. marah (angry) 15.9 [14.1]

2. MALU (SHAME) 16.2 [13.0]

3. kasihan (sympathy, pity) 16.3 [12.1]

4. berani (dare to, to feel brave, willing [to do something challenging]) 16.5 [12.0]

5. jujur (honest) 17.0 [11.0]

6. benci (hate) 19.0 [14.2]

7. baik hati (kind, generous, sympathetic) 19.3 [11.9]

8. ingin (want, desire) 19.6 [13.0]

9. takut (afraid) 20.0 [14.0]

10. sopan (polite, respectful) 20.5 [12.0]

11. sedih (sad) 21.0 [12.1]

12. kesal (fed up, angry) 21.3 [12.1]

12. bahagia (happy) 21.3 [13.9]

13. gembira (glad) 22.0 [14.9]

14. cinta (love) 22.1 [15.0]

15. yakin (to feel certain, convinced, dedicated) 22.6 [13.1]

16. ibo (pity, compassion) 23.0 [13.0]

17. akal (idea, wile, insight) 23.1 [16.0]

18. merajuk (sullen expression of unhappiness, disappointment) 23.3 [14.3]

18. bercito-cito (to have ambitions, desires, dreams) 23.3 [13.4]

19. sadar (aware, conscious [of]) 23.9 [12.3]

20. cek'inan nian (intense wanting, desire) 24.2 [15.6]

21. idak sampai hati (to not have the heart [to do $\mathrm{X}$ ]; sympathy) 24.5 [14.4]

22. rindu (to miss [a person or place]) 24.9 [11.0]

23. terkejut (startled, surprised) 25.0 [13.5]

24. rengam (fed up, frustrated, pissed off) 25.4 [17.1]

25. sakit hati (offended, angry, spiteful) 27.0 [13.0]

25. curiga (suspicious) 27.0 [10.4]

26. jöik (disgust; contempt) 27.2 [15.0]

27. ikhlas (sincere acceptance [of fate, outcome, etc.]) 27.9 [14.7]

28. niat (desire, want, intend, be determined to) 28.0 [14.0]

29. kecewa (disappointed) 28.9 [11.4]

\section{Californian English}

1. love 8.3 [11.0]

2. stressed out 10.0 [10.3]

3. happy $10.3[10.1]$

4. sorry 11.7 [11.5]

5. bored 12.7 [10.8]

6. $\operatorname{mad} 14.5$ [11.7]

7. sad $15.5[10.1]$

8. frustrated 16.1 [10.2]

9. excited 16.4 [12.1]

10. hope 16. 6 [14.0]

11. annoyed 16.8 [10.8]

12. confused $17.6[10.1]$

13. pissed off 18.1 [15.6]

14. hate 18.9 [15.4]

15. upset 20.3 [11.5]

16. depressed 20.6 [12.4]

17. disappointed 21.5 [9.3]

18. surprised 22.2 [10.2]

19. irritated 22.3 [12.0]

20. embarrassed 22.6 [11.0]

21. respect 23.1 [13.7]

22. scared 23.3 [12.0]

23. amazed 24.8 [11.6]

24. relieved 25.5 [11.5]

25. lonely $25.6[12.0]$

26. afraid 26.2 [11.2]

27. anxious 27.1 [13.8]

28. shocked 28.4 [10.7]

28. amused 28.4 [13.1]

29. calm 28.8 [12.5] 


\section{Table 1}

(Continued)

\section{Bengkulu Malay}

Galifornian English

30. menghargai (to value, respect, honor [someone or something]) 29.6 [15.0]

31. insaf (come to one's senses, realize the wrongness of one's actions) 29.7 [12.0]

32. iri (envy) 30.0 [13.1]

30. jealous 28.9 [12.7]

31. offended 29.7 [11.0]

32. guilt 30.2 [10.7]

32. lapang dado (1) willingly accept w/o resentment;

2) relieved) 30.0 [14.2]

33. pandang-memandang (to feel mutual respect) 30.1 [17.6]

34. merentak-merenyuk (to have a tantrum, fit of anger) 30.6 [17.0]

35. dendam (to desire vengence) 30.7 [11.8]

36. harok-harok cemé (hopeful but worried that hopes may not be realized) 30.8 [16.1]

37. tobat (realize the wrongness of one's actions, repent, reform) 31.5 [11.0]

38. bermaksud (to intend; to pursue a goal) 31.9 [15.1]

39. was-was (hesitant, uncertain, unsure) 32.0 [12.3]

40. menderita (suffer) 32.8 [9.95]

41. asmara (passionate love) 34.3 [14.6]

42. emosi (anger) 34.4 [12.7]

43. bijaksana (wise) 34.6 [14.6]

44. waspada (cautious, alert) 34.7 [13.3]

33. disgusted $31.3[11.0]$

34. regret $31.4[10.5]$

35. pride 31.8 [12.0]

36. pity 32.5 [13.8]

37. joy 33.5 [13.4]

38. sympathy 33.9 [11.9]

39. passion 34.6 [14.6]

40. frightened 34.7 [8.98]

41. miserable 35.2 [11.5]

42. compassion 35.7 [12.8]

43. outraged 36.1 [12.0]

44. terrified 38.5 [9.77]

45. envious $38.8[10.6]$ experience of the uncanny]; 2) to be powerfully attracted by cuteness [of an infant, etc.]) 35.9 [13.5]

46. Ke mano awak pacak nyuruk muko iko? "Where can I hide my face?", shame) 38.0 [17.5]

47. prihatin (concerned, worried) 38.1 [12.4]

48. frustrasi (frustrated) 40.1 [11.4]

47. lust $39.7[12.4]$

48. grief 40.9 [10.6]

49. SHAME 41.0 [9.66]

50. contempt 41.9 [11.7]

51. ecstasy 43.4 [11.8]

the Bengkulu sample (indeed, the reverse is true, as the average standard deviation in California [11.7] is actually lower than that in Bengkulu $[13.5])^{5}$

${ }^{5}$ This finding is additionally reassuring given the danger of kibitzing entailed by the fact that 22 of the 80 Bengkulu participants lived in the same household as another participant. 
Inspection of Table 1 reveals a substantial difference in the perceived frequency with which the terms malu and shame, respectively, are employed in discourse compared to other common emotion terms in the two cultures, with the former ranking second in Bengkulu, while the latter ranks fortyninth in California. ${ }^{6}$ The connections between discourse, experience, and cultural marking are complex, hence this measure should not be taken as a definitive assessment of the extent to which shame is attended to or otherwise culturally elaborated in each of the two cultures. Nevertheless, the difference across the two cultures in the perceived frequency with which shame is discussed is consistent with more general observations concerning cross-cultural differences in the importance of shame and its salience in everyday experience (cf. Fessler, 1995, 2002; Hofstede, 1991; Karen, 1992). Having established that there are at least preliminary reasons for concluding that the concept of shame is considerably more prominent in Bengkulu than in California, I therefore sought to compare the experience of this emotion in the two cultures by examining situations in which shame occurs.

\section{Study 2 - Events in Which Shame Occurs}

Reasoning that the most ecologically valid portrait of people's understanding of subjective experience is one derived from spontaneous discussions thereof, in Bengkulu I collected 305 verbatim or near-verbatim records of instances in which people described themselves or someone else as feeling malu. $^{7}$ These cases can be considered fairly representative of situations in which Bengkulu villagers see themselves or others as feeling shame since a) informants were unaware of my research goals, b) my prolonged presence led people to incorporate me into their social networks, and c) in many instances I was merely a bystander rather than a participant in discussions.

\footnotetext{
${ }^{6}$ Of relevance for discussions which follow, the fourth most common Bengkulu term, 'to dare,' is typically used in contexts of disparities of power. For example, when asked why she had been reticent to visit my home during the early months of fieldwork, an elderly woman replied "I didn't dare, I thought of you as an important foreigner. Now I call you 'little brother' [i.e., have assimilated you to the status of village member], so I'm not afraid to visit you."

${ }^{7}$ The data set does not include conventionalized or ritualized uses of the term malu. Conclusions derived from an initial analysis of this data set were previously published in Fessler, 1999.
} 
While the use of naturally-occurring instances of shame events has high ecological validity, it is a laborious means of collecting data. Even in a culture which dramatically hypercognizes shame, despite nearly constant immersion in the social life of the village I averaged only one shame event recorded for every two full days of research in Bengkulu. For reasons of expediency in California I therefore asked 12 undergraduate research assistants to solicit from each of 20 or more friends, family members, and associates an account in which someone was described as having felt shame; research assistants were told to limit their solicitations to middle- and upper-middle class individuals who had been born and raised in Southern California and spoke English as a native language. In order to assuage participants' concerns about revealing potentially damaging information concerning themselves, research assistants informed participants that (as in much of the Bengkulu data) the account could focus on a third party, and that the protagonist in the account need not be identified; participants were also told that, if they wished, they could disguise their own experiences, describing them as if they had happened to someone else. Participants were informed that the research assistant would not convey the identity of the participant to me. Two hundred and eighty one accounts of shame events were collected.

\section{Categorizing Shame Events}

Like much data gathered through participant observation, the Bengkulu events are embedded in a matrix of cultural beliefs and parochial social relationships. Because understanding the Bengkulu cases thus often requires familiarity with both local ideas and the history of relationships, it is not feasible to subject these events to examination by third party coders. ${ }^{8}$ I therefore coded the data myself. In the interests of maintaining comparability, I also coded the Californian cases.

In order to compare the frequency of different types of experiences in the shame stories from California and Bengkulu I sought to create a set of categories, each of which encompassed a notable fraction of the stories

\footnotetext{
${ }^{8}$ Although some of the more educated citizens of Bengkulu could conceivably manage this task, it would be unethical to ask individuals from the region to examine this material given the potential damage to the village's reputation.
} 
from one or both cultures. Because emotions can be usefully categorized on the basis of family resemblance (Barrett, 1995; Shaver et al., 2001; Shaver, Wu \& Schwartz, 1992; Wicker, Payne \& Morgan, 1983), in classifying shame events I employed a list-of-features approach based on contrasts drawn in the literature between various emotions; so as to avoid arbitrary distinctions, I also created combination categories for stories that fit equally well into more than one category. The categories are as follows:

- Classical shame events: Focus on concern with others' actual or imagined negative evaluations; Often stem from violation of a relatively important social standard; Characterized by feeling small, wishing to avoid being seen by others; Often involves shrinking posture, gaze aversion, flight, hiding; Little or no emphasis on reparations, penance, etc. (Barrett, 1995; Ferguson, Stegge \& Damhuis, 1991; Gilbert, 1997; Lazarus, 1991; LindsayHartz, de Rivera \& Mascolo, 1995; Mascolo \& Fischer, 1995; Mikulincer \& Florian, 1997; Smith, Webster, Parrott \& Eyre, 2002; Tangney, 1995; Wallbott, 1998; Wallbott \& Scherer, 1995; Wicker et al., 1983).

Example (from Bengkulu): (young adult male): "This girl I knew from school, she got knocked up, and then her belly started to get really big, so everyone found out about it. Well, the guy didn't want to take responsibility, and he ran off to [a distant region]. She wouldn't come out of her house for days, she just hid in her room all the time. Then one day she killed herself, drank Baygon [insecticide] right there in her bedroom. Man, it was horrifying to see [the body]. She killed herself because she couldn't stand people talking about her all the time, couldn't stand feeling malu [about being pregnant out of wedlock]."

- Guilt-like events: Emphasis on remorse or regret; Often stem from inflicting harm on another; Often involve a desire to compensate the victim, apologize, and/or punish the self; Little or no evidence of concern with others' negative opinions of the actor; Little or no emphasis on public nature of failure, no evidence of a desire to avoid visibility, no reports of shrinking, feeling small, etc. (Barrett, 1995; Baumeister, Stillwell \& Heatherton 1995; Ferguson et al., 1991; Gilbert, 1997; Lindsay-Hartz et al., 1995; Mascolo \& Fischer, 1995; Tangney, 1995, 1998; Wicker et al., 1983; Olthof, Schouten, Kuiper, Stegge \& Jennekens-Schinkel, 2000; Smith et al., 2002; Wallbott \& Scherer, 1995). 
Example (from California): (young male) "Yeah I was like ... I don't know, at the time I had what I called the "drop syndrome" I woke up one day and didn't want to be with someone. Well, my girlfriend at the time asked at prom if I wasn't interested and if I just wanted to be friends, but I lied and said no. And, back then I was different person ... right now, I'm all about being blunt, if it was now, I'd be up front with [her] ... back then, I was a pussy, so I broke up with her via e-mail, really hurt her bad. I totally regret it now. It was totally not fair, not fair to her at all. I feel like crap about it now. If I could do it again I would totally go about it a different way."

- Embarrassment-like events: Often stem from violations of conventions rather than moral rules, particularly with regard to questions of decorum, modesty, etc.; May involve public attention in the absence of any wrongdoing; Often viewed as amusing at the time or in retrospect by observers and/or focal individual; Often involve blushing, smiling, giggling, and/or covering of the mouth with the hand Babcock \& Sabini, 1990; Keltner \& Buswell, 1996, 1997; Lewis, 1995; Tangney, Miller, Flicker \& Barlow, 1996).

Example (from California): (adult female, recalling early adolescence) "Once, I slipped and fell down in the line at the grocery store while buying tampons for my mom and people laughed because I had a huge box of tampons. I felt really, really bad - my face turned really red, and my sister saw from outside because she was waiting in the car and I was in front of the window and I could see her cracking up from the store, which made it even worse."

To these distinctions I then added the following categories derived from inspection of the cases:

- Shyness events: Reticence to interact with strangers, reticence to engage in a variety of relaxed or intimate behaviors (eating, laughing, etc.) in front of unfamiliar others; Associated with nervousness, anxiety, discomfort.

Example (from Bengkulu): (At a small feast attended by a handful of neighbors) Author (to several adult men): "You guys are really eating a lot! I noticed the other day at the mosque when they served cookies after prayers nobody ate very much - why?" $\mathrm{Z}$ (middle-aged man): "Because we were malu with the visitors!" A: "So you're not malu now?" Z: "Of course not, it's just 
us folks here, we're all one big family, so we can relax, eat a lot. But at the mosque there were outsiders there, people from other villages, and we were malu, so we didn't eat very much."

- Subordinance events: Elicited by interaction with an individual acknowledged to be superior in the social hierarchy; No immediate failure or wrongdoing on the actor's part; Often associated with reticence to act, feeling small, a desire to flee, gaze aversion, etc.

Example (from Bengkulu): I'm sitting in a shop across the alley from the Head of the Village's house. A young man from [outlying area] walks down the alley, glancing around, shoulders drooping; he wears clean but worn and out of fashion clothes. Pauses at the steps, calls out a greeting. After a minute the Head of the Village appears and greets the young man. Young man's shoulders droop even further, he stares at the ground, shifts his weight from foot to foot, and tugs at his shirt. Starts to say something but stops. Head of the Village offers him a seat and asks what he wants. Young man hesitates, stammers for a minute, then says that he has come to invite Head of the Village to a wedding. Old man sitting next to me in shop: "Boy, he's so malu with the Head of the Village (that) he almost forgot why he came!" Author: "Why is he malu?" Old man: "Because that's the Head of the Village!" A: "So?" Old man: "So, he's just a poor fella, young, barely a man, not even related to anyone around here - he's a 'little guy,' a nobody, so he's malu to talk to a 'big guy' like the Head of the Village."

\section{Discussion}

Inspection of Table 2 reveals important commonalities between the Californian and Bengkulu data. First, classical shame situations constitute the majority of cases in both, suggesting that this core aspect of the emotion is easily identifiable in two disparate cultures. Consistent with the conclusion that this category reflects universal features of a discrete emotion, as displayed in Table 3, less systematic ethnographic descriptions gleaned from the Human Relations Area Files and similar literature provide suggestive evidence that shame occurs in such situations in a wide variety of cultures: ${ }^{9}$

\footnotetext{
${ }^{9}$ Ethnographers often use the word 'shame' in a wide variety of ways. The works cited here provide evidence of an aversive emotional experience, often involving flight or hiding,
} 


\section{Table 2}

Categorization of shame events from two cultures. Californian stories were provided by 281 anonymous individuals in response to a request for a description of an event in which someone felt shame. In Bengkulu, participant observation was used to collect instances in which speakers used the word malu to describe their own or someone else's subjective state.

\begin{tabular}{lcc}
\hline & California & Bengkulu \\
\hline Classical shame events & $146(52.0 \%)$ & $172(56.4 \%)$ \\
Guilt-like events & $57(20.3 \%)$ & 0 \\
Embarrassment-like events & $21(7.47 \%)$ & $56(18.4 \%)$ \\
Subordinance events & 0 & $28(9.18 \%)$ \\
Shyness events & 0 & $5(1.64 \%)$ \\
Classical shame + guilt events & $43(15.3 \%)$ & 0 \\
Classical shame + embarrassment events & $10(3.56 \%)$ & $32(10.5 \%)$ \\
Classical shame + subordinance events & 0 & $5(1.64 \%)$ \\
Subordinance + shyness events & 0 & $6(1.97 \%)$ \\
Unclassifiable & $4(1.42 \%)$ & 0 \\
Total & 281 & 305 \\
\hline
\end{tabular}

A second feature of the Californian and Bengkulu data sets is that embarrassment-like events are evident in both, suggesting that there is substantial overlap between the experience of embarrassment and the experience of shame in both cultures. Similarly, shame and embarrassment seem to overlap in ethnographic descriptions of Rarámuri (Mexico) (Merrill, 1988) and Bedouin (Egypt) (Abu-Lughod, 1986) culture, and linguistic analyses reveal connections in Arabic and Javanese (Al Jallad, 2002). The greater prominence of embarrassment-like cases in the Bengkulu data compared to the Californian material may reflect the fact that the Kota Bengkulu dialect of Malay does not differentiate between shame and embarrassment, a topic to which I will return later.

In addition to the central parallels between the Californian and Bengkulu data, a number of distinct differences are also readily apparent. First, although guilt-like events are prominent in the Californian corpus, they are wholly absent from the Bengkulu data. It is possible that, because 


\section{Table 3}

Cultures for which published material provides direct or suggestive evidence that people experience a shame-like emotion in classical shame situations. ${ }^{1}$ (Messenger, 1971), ${ }^{2}$ (Friedl, 1962), ${ }^{3}$ (Boehm, 1984), ${ }^{4}$ (Wikan, 1980), ${ }^{5}$ (Swartz, 1991), ${ }^{6}$ (Maxwell, 1983), (Richards, 1956), ${ }^{7}$ (van Beek, 1994), ${ }^{8}$ (Hutchinson, 1996), ${ }^{9}$ (East, 1939), ${ }^{10}$ (Barth, 1981), ${ }^{11}$ (Bodding, 1924; Culshaw, 1949), ${ }^{12}$ (Obeyesekere, 1981), ${ }^{13}$ (Parish, 1991), ${ }^{14}$ (Creighton, 1990; Crystal, Parrott, Okazaki \& Watanabe, 2001; Lebra, 1983; Miyake \& Yamazaki, 1995), ${ }^{15}$ Korean (Yang \& Rosenblatt, 2001), ${ }^{16}$ (Wolf, 1972), ${ }^{17}$ (Spiro, 1996), ${ }^{18}$ (Mulder, 1996; Sharp \& Hanks, 1978), ${ }^{19}$ (Lambrecht, 1932), ${ }^{20}$ (Rosaldo, 1983), ${ }^{21}$ (Dentan, 1979), ${ }^{22}$ (Bolyanatz, 1994; Epstein, 1992; Fajans, 1983) (Strathern, 1977), ${ }^{23}$ (Myers, 1979) (Tonkinson, 1978), ${ }^{24}$ (Sachdev, 1990), ${ }^{25}$ (Lery, 1973), ${ }^{26}$ (Gregor, 1977), ${ }^{27}$ (Kennedy, 1978), ${ }^{28}$ (Merrill, 1988), ${ }^{29}$ (Nash, 1970), ${ }^{30}$ (Simmons, 1960)

\begin{tabular}{|c|c|}
\hline Europe & Rural Irish, ${ }^{1}$ Rural Greek, ${ }^{2}$ Montenegran ${ }^{3}$ \\
\hline $\begin{array}{l}\text { Middle East \& } \\
\quad \text { Africa }\end{array}$ & $\begin{array}{l}\text { Urban Egyptian, }{ }^{4} \text { Mombasa Swahili (urban East Africa) }{ }^{5} \text { Bemba } \\
\text { (Zambia), }{ }^{6} \text { Dogon (Mali, West Africa), }{ }^{7} \text { Nuer (Sudan), }{ }^{8} \text { Tiv (Nigeria) }\end{array}$ \\
\hline Central Asia & $\begin{array}{l}\text { Pukhtun (Pakistan-Afghanistan), }{ }^{10} \text { Santal (India), }{ }^{11} \text { Sri Lanka, }{ }^{12} \text { Newar } \\
(\text { Nepal })^{13}\end{array}$ \\
\hline East Asia & Japanese, ${ }^{14}$ Korean, ${ }^{15}$ Rural Taiwanese ${ }^{16}$ \\
\hline Southeast Asia & $\begin{array}{l}\text { Burmese, }{ }^{17} \text { Thai, }{ }^{18} \text { Mayawyaw (Philippines), }{ }^{19} \text { Ilongot (Aboriginal } \\
\text { Philippines), }{ }^{20} \text { Semai (Aboriginal Malaysia) }{ }^{21}\end{array}$ \\
\hline Oceania & $\begin{array}{l}\text { Melanesian, } 22 \text { Pintupi \& Mardudjara (Aboriginal Australia), }{ }^{23} \text { Maori, } \\
\text { Tahitian }^{25}\end{array}$ \\
\hline New World & $\begin{array}{l}\text { Mehinaku (Aboriginal Central Brazil), }{ }^{26} \text { Tarahumara (Mexico), }{ }^{27} \text { Rará- } \\
\text { muri (Mexico), }{ }^{28} \text { Maya (Mexico), }{ }^{29} \text { Rural Peruvian } 30\end{array}$ \\
\hline
\end{tabular}

guilt is often less dependent on considerations of public exposure than shame, the difference in the frequency of guilt-like events merely reflects differences in the methods used in California and Bengkulu - perhaps Californian participants included many cases of guilt-like events because they could easily report on private experience, whereas the Bengkulu data, derived from spontaneous discussions, may have been biased against experiences that did not involve a public component. Although I cannot rule out this possibility, it is striking that guilt-like events never occur in the Bengkulu corpus, and this despite the fact that I was considered a close friend, confidant, and/or member of the immediate family by at 
least 13 key informants. People often shared their intimate hopes and fears with me, yet did not recount guilt-like events when talking about malu. This is not because they preferred some other more precise emotion term instead. The Kota Bengkulu dialect does not contain a word that can be readily translated as 'guilt' - sesal is the closest, but this term, best glossed as 'regret,' merely describes the negative experience accompanying a retrospective desire to have acted differently than one has done. ${ }^{10}$ Guilt-like events were simply not discussed in Bengkulu. On a number of occasions I specifically probed informants regarding "having felt badly because you did something that hurt someone, even though no one ever found out about it," but such questions failed to elicit a clear response - people seemed hesitant or confused, at most describing their subjective state as one of regret; often, they simply remarked on the wrongness of harming others, making no reference to emotions. These observations suggest that this fundamental difference between the Californian and Bengkulu data is not a methodological artifact. Consistent with this conclusion, in a large crosscultural study, Wallbott and Scherer (1995) found that participants from collectivistic cultures like that of Bengkulu reported shame experiences that were central to the profile of this emotion. In contrast, participants from individualistic cultures like that of the Californian sample often reported shame experiences that greatly resembled guilt experiences. People from individualistic cultures thus seem more likely to conflate, equate, or blend shame and guilt than do people from collectivistic cultures.

\footnotetext{
${ }^{10}$ Examining the national language of Indonesia, Fontaine et al. (2002) and Heider (1991) equate the term bersalah with guilt. In the Kota Bengkulu dialect, bersalah, which literally means 'to be in the wrong, to have erred,' connotes the incorrectness of an action more than the emotional state that results; as in Fontaine et al.'s results from university students, Bengkulu villagers equate the term with berdoso (berdosa in Indonesian), 'to sin.' While these terms concern issues of potential relevance to guilt, at least in the Bengkulu village studied, they are not foregrounded as emotions. Both Fontaine et al. and Heider report that bersalah has close links to 'fear,' a feature not prominent in Western semantic domains of guilt (Shaver, Schwartz, Kirson \& O’Connor, 1987) and largely absent from Western descriptions of guilt. Whereas the latter emphasize the repair of damaged relationships and/or the punishment of the self, in cases of bersalah, individuals simply recognize that they are at fault and therefore fear retribution or divine punishment. Lastly, the terms tobat and insaf (numbers 36 and 37 in Table 1) have the connotation of 'turning over a new leaf' rather than guilt-ridden self-remonstration.
} 
In addition to the question of the presence or absence of guiltlike events, a second important difference between the Californian and Bengkulu data is that, while subordinance shame events and shyness events occur in the Bengkulu corpus, such cases are absent from the Californian collection. The presence of the subordinance and shyness events in the Bengkulu material is not explicable in terms of polysemy - the term malu does not encompass homonyms. Using hypothetical examples I asked a focus group of five young Bengkulu men whether the subjective experience of malu in prototypical situations of shyness or subordinance was the same or different from the subjective experience of malu in classical shame situations. While most of the young men conceded that the classical shame scenarios would likely elicit a more intense emotional response than the shyness scenarios, they adamantly insisted that the underlying feelings and action tendencies were the same, remarking that feeling small, wanting to hide, and experiencing an inability to maintain direct gaze occurred in all three types of situations. This claim is reinforced by my own observations in those cases where I witnessed subordinance or shyness events directly, as the behavioral components were indeed those which Western investigators associate with classical shame and embarrassment situations (Keltner \& Buswell, 1997; Keltner \& Harker, 1998; Keltner, Young \& Buswell, 1997; Wallbott, 1998). In light of the continuity of the malu experience across classical shame events, subordinance events, and shyness events, it is therefore striking that Californian participants did not produce any examples of the latter categories.

Some of the important differences between the Bengkulu and Californian corpora may reflect differences in the methods employed in the two societies, as the Bengkulu malu events were naturally-occurring but the Californian shame events were recounted in response to an explicit request from a researcher. It is plausible that, compared to other instances of shame, prototypical exemplars are both more easily recalled and more frequently judged by participants to be an appropriate response to requests for stories involving shame. As a consequence, the Californian corpus may contain a higher proportion of locally prototypical events than the Bengkulu corpus. Other investigators working with Western populations have noted links between shame and shyness (Crozier, 1990; Henderson, 2002; Keltner et al., 1997; Mosher \& White, 1981), suggesting that this 
association may well be present in Californian culture but, being somewhat more peripheral to the concept of shame, shyness events were simply not elicited by my requests for stories concerning this emotion. In contrast, because few existing data shed light on the relationship between subordinance and shame in contemporary Western populations, it is unclear whether the marked difference in this regard between the Bengkulu and Californian corpora is similarly a methodological artifact, or whether it reflects a fundamental difference between the two cultures. It is therefore important to consider additional sources of information about the relative prominence of subordinance in the culturally-shaped experience of shame in these two populations.

Lexical labels for emotions are important both because they allow the investigator to draw distinctions between various types of experiences and because they are the tip of that cultural iceberg which complexly shapes how individuals experience and report on emotions (Shaver et al., 1987; Shaver et al., 1992). If our goal is to achieve a fuller understanding of a panhuman emotion that is differentially construed in different cultures, it therefore follows that examining emotion lexicons may shed light on the properties of shame that are variously highlighted or ignored by the two cultures at issue.

\section{Study 3 - The Semantic Domain of Shame}

\section{A Modification of Heider's Emotion Synonym Mapping Technique}

Investigations of the relationships between emotion terms often employ sorting, rating, or comparison tasks in combination with analytic techniques such as multidimensional scaling (see Fontaine et al., 2002; Moore, Romney, Hsia, \& Rusch, 1999; Russell, 1991; Scherer, 1997; Scherer \& Wallbott, 1994; Shaver et al., 1987; Shaver et al., 2001; Shaver et al., 1992). These methods allow for the evaluation of the degree of similarity between an emotion of interest and multiple other emotions. However, these methods are limited in that they may have difficulty addressing intransitive relationships between emotions. If emotion $\mathrm{A}$ is multifaceted it can be similar to emotion $\mathrm{B}$ on some counts and similar to emotion $\mathrm{C}$ on other counts even though $\mathrm{B}$ and $\mathrm{C}$ have little in common with one another. Multidimensional scaling adds additional dimensions to capture such relationships, but it is only possible to do so with respect to the level 
of multiplicity that prevails across the larger set of emotion terms examined - if the facets along which emotion A varies are unique to emotion A, this multiplicity may not appear in the final representation of the semantic domain.

Heider (1991) presents an alternative method of mapping the semantic domain of emotion. Participants are asked to provide one synonym for each target emotion term; the between-subjects frequency with which a term is given as the synonym for another is taken as indicating the degree of similarity between the two terms in the semantic domain. ${ }^{11} \mathrm{~A}$ map of the domain is then drawn using lines linking synonyms. Although intransitivity precludes accurate graphical representation of similarity in euclidean space (Heider 1992:26-7), this problem is easily overcome using numerical notations of synonym frequency placed adjacent to the linking lines. This technique places no constraints on the number of dimensions along which each emotion term can vary, since terms can differ in the number of other terms to which they are linked.

Because not every target term elicits a response from every participant, the number of times a given synonym is recorded for a given target term must be converted to a percentage of the total number of responses for that target, a figure I call the connection strength. Connection strength is directional - for emotions $\mathrm{A}$ and $\mathrm{B}$, the connection strength of $\mathrm{A}$ to $\mathrm{B}$ represents the frequency with which $\mathrm{B}$ was given as a synonym in response to $\mathrm{A}$ as a prompt; this is easily represented using an arrow and associated numerical value. While a pair of terms may be linked in two directions (i.e., $\mathrm{B}$ is given as a synonym for $\mathrm{A}$ and $\mathrm{A}$ is given as a synonym for $\mathrm{B}$, represented using a two-headed arrow with two respective numerical values), this need not be the case. In order to avoid crowding the map with rare (and hence presumably idiosyncratic) synonyms, a minimum connection strength of 5.5, summed across the two terms in the event

\footnotetext{
${ }^{11}$ Like techniques that average responses across participants, Heider's approach presumes that cultural schemas of emotion are sufficiently widely shared that a betweensubjects design will capture core features of the schemas at issue. While a strong case can be made that cultures are heterogeneous bodies of information which are incompletely shared across individuals (Aunger, 1999), extensive conversations and interviews suggest that the meanings of most emotion terms are widely shared in Bengkulu. The terms appearing in the Californian map generally have high prototypicality ratings according to Shaver et al. (1987), suggesting that cultural sharing of these terms is also likely to be high.
} 
of bidirectionality, was arbitrarily selected as a threshold for inclusion. Because participants' responses are not constrained to the list of terms given as prompts, despite the extensive nature of the list, gaps can appear in the results (i.e., we know the connection strength of A to $\mathrm{X}$ but, because $\mathrm{X}$ was not used as a prompt [indicated on the map by the @ symbol], we do not know the connection strength of $\mathrm{X}$ to A). ${ }^{12}$ Finally, connection strength must be appraised in light of the number of terms connected to a target term. Because prototypical terms are likely to elicit many different synonyms while peripheral terms are likely to elicit prototypical terms, prototypical terms will exhibit more connections than peripheral terms; due to 'vote splitting,' a given link from a prototypical term will therefore often display weak directional connection strength compared to the connection strength from the corresponding peripheral term.

\section{The Californian Semantic Domain of Shame}

A focus group of 10 Californian undergraduates used free recall and discussion to generate a list of 453 English emotion terms, the order of which was then randomized. Sixty middle and upper-middle class native speakers of English who were born and raised in Southern California then completed a paper-and-pencil form on which they were asked to provide a single synonym for each of the 453 terms. Participants were instructed to limit their responses to emotion words; they were also told that they could use the same word as a response multiple times if they chose to do so, and that a word did not need to be on the list in order for them to use it as a response. They were asked to complete the form within a 24 hour period, and were instructed not to consult others or use a dictionary or thesaurus. Two individuals left more than $10 \%$ of the lines blank and were therefore dropped from the study, leaving a sample of 58 participants (30 women

\footnotetext{
${ }^{12}$ The content of the list of prompt terms inevitably shapes the contours of the resulting map, as infrequently used terms which do not appear on the list are less likely to be given as responses sufficiently often to pass the threshold for inclusion, resulting in an incomplete map. The procedure used here sacrifices maximal completeness for the sake of expedience, since compliance rates decline substantially with very long lists of prompt terms. This step is defensible given that a) the lists of prompt terms were generated by members of the cultures at issue, and b) participants were free to employ response terms that were not on the lists.
} 


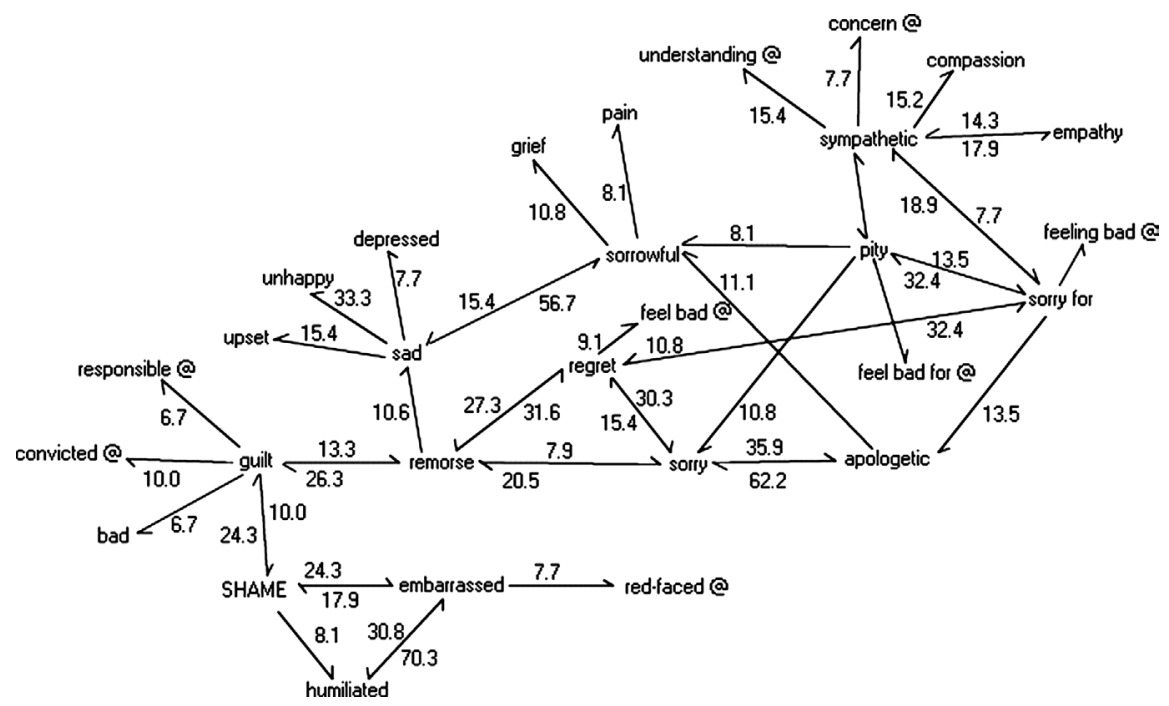

Map 1. The semantic domain of 'shame' in middle- and upper-middle class Southern California English.

$\mathrm{N}=48$. Numbers indicate the percentage of respondents who provided the term at the end of the arrow as a synonym for the target term. Minimum for the inclusion of the term in map $=5.5$ (summed in the event of bidirectionality). @ = term not given as a prompt.

and 28 men, age 19-53, mean 23). Map 1 presents the portion of the total Californian map containing those terms that are linked to 'shame. ${ }^{\text {, } 3}$

\section{Discussion}

Inspection of Map 1 reveals a number of prominent features of the Californian semantic domain of shame. First, purely shame-like experiences are relatively unelaborated in the Californian lexicon, as the immediate cluster includes only three terms. Second, shame is not linked to any terms clearly focusing on social rank, nor are there any connections to shyness. Third, consistent with the prominence of embarrassment-like events in the Californian shame stories, shame is tied to embarrassment. Fourth, shame is intimately linked to guilt, an emotion linked to an extensive cluster involving sadness, remorse, pity, and so on (note also that terms

${ }^{13}$ For the sake of clarity, interconnected clusters flowing outward from 'upset,' 'unhappy,' 'depressed,' 'grief,' and 'pain' are not shown, as these do not link back to 'shame.' 
involving 'feeling bad' form additional linkages between 'guilt,' 'regret,' and 'sorry for'). This pattern, consistent with the previous finding that $20.3 \%$ of Californians' shame stories fall into the guilt-like category and $15.3 \%$ into a mixed shame/guilt category, is in keeping with long-standing anthropological claims that guilt is more prominent than shame in the West (Benedict, 1946; Piers \& Singer, 1953), a difference congruent with a cultural emphasis on autonomy, individual choice, or 'voluntarism' (Sabini \& Silver, 1997). ${ }^{14}$ The associations with guilt are consistent with existing descriptions of this emotion (Baumeister, Stillwell, \& Heatherton, 1995; Ferguson et al., 1991; Lindsay-Hartz et al., 1995; Tangney, 1995, 1998) as it focuses on remorse, regret, empathy with an individual who is suffering, and so on.

There are strong grounds for supposing that shame and guilt are distinct emotions, as they are associated with different relational themes, different action tendencies, and different display behaviors (or, in the case of guilt, the absence thereof - [Wallbott, 1998; Zahn-Waxler \& Robinson, 1995]) (Lindsay-Hartz et al., 1995; Mikulincer \& Florian, 1997; Scherer, 1997; Scherer \& Wallbott, 1994; Smith et al., 2002; Wallbott \& Scherer, 1995). Despite the distinct character of these two emotions, Californian participants strongly equate them with one another, often blurring the distinctions between them. In California both shame and guilt regulate social interaction with respect to core rules and principles for behavior. Because they perform the same elementary social function in California, shame and guilt may often co-occur. Emotions may be judged similar on the basis of co-occurrence rather than as a result of intrinsic similarity (Schimmack \& Reisenzein, 1997), a factor that may account for their intimate lexical association in the Californian semantic domain. Together with the presence of many guilt-like stories in the Californian shame corpus, these observations suggest that, if our primary objective is to explore the underlying universal properties of

\footnotetext{
${ }^{14}$ This does not bear on clinicians' claims that shame is an important factor in psychological distress and psychopathology in the West (Lewis, 1987; Tangney, 1999; Tangney \& Dearing, 2002). Cultural hypocognizing may actually contribute to the pathogenicity of an emotion, as the absence of elaborate cultural models means that few institutional or conventional processes are likely to exist that assist individuals in coping with the experiences that elicit the emotion (Levy, 1973).
} 
panhuman shame, investigations conducted in individualistic cultures such as California constitute a suboptimal starting point, as the domination of this conceptual realm by guilt limits the power of data supplied by middleand upper-class Southern Californians to shed light on key features of shame. ${ }^{15} 16$

\section{The Bengkulu Semantic Domain of Malu}

Ten literate informants (6 male, 4 female) were asked to create master lists of words that could be construed as emotions (cf. Shaver et al., 2001). The informants were told to consult friends, family members, and neighbors, and record all terms which seemed appropriate. One informant was asked to search the official unabridged Indonesian dictionary (Departemen Pendidikan dan Kebudayaan, 1990) for emotion words, as there is considerable overlap between the national language of Indonesia and the contemporary Kota Bengkulu dialect of Malay. He was told to choose only those emotion terms which were used with considerable frequency in the village, or which had close cognates in the local dialect; in the latter case, he was to record the cognate rather than the Indonesian term. Working with two adult male informants, I combed the resulting list, discarding what we unanimously considered non-emotion words or obscure terms. This produced a master list of 520 words, the order of which was then randomized. Together with the same instructions as accompanied the task in California, this list was distributed in written form to 80 literate informants, evenly divided between males and females, with subjects ranging in age from approximately 15 to 45 years (exact

\footnotetext{
${ }^{15}$ My findings are similar to those of Shaver et al. (1987), who report that participants in Colorado judge shame to be most similar to guilt, regret, and remorse. Given cultural similarities between the Californian participants and subjects in other studies conducted in North America, it is likely that an individualistic culture which hypercognizes guilt is largely responsible for the difficulty encountered by some investigators (e.g., Tangney, 1992) in categorically differentiating shame-evoking and guilt-evoking situations.

${ }^{16}$ Eid \& Diener (2001) report that guilt has greater normative significance in two collectivistic cultures than in two individualistic culture. While this finding is consistent with the heightened emphasis on social solidarity characteristic of collectivism, it should not be interpreted as bearing on the centrality of others' opinions in the regulation of behavior in collectivistic cultures, a factor that elevates shame over guilt in the cultural hierarchy of moral emotions.
} 
ages are rarely known). Participants were compensated with a ticket for the lottery described in Study 1. Seven lists were not returned and three were discarded because the participant had not understood the task or had left more than $10 \%$ of the lines blank. Seventy lists remained (38 male, 32 female).

Using the same figure of 5.5 as the cut-off frequency for inclusion in the final map, I found that malu is linked to a number of distinct clusters of terms. The two principal clusters are displayed here, each on a separate map for clarity.

\section{Discussion}

Map 2 illustrates a cluster centering on inadequacy and social rejection. While employing some terms which English speakers do not identify as emotions, ${ }^{17}$ this cluster can nevertheless readily be understood as a lexical instantiation of classical shame - individuals experience an aversive emotion because they fail to measure up to social standards, leading them to want to hide their faces, and leading others to evaluate them negatively.

Two lacunae in Map 2 are noteworthy. First, there is no distinct term for embarrassment in the Kota Bengkulu dialect. Second, neither in this nor in any adjacent constellation does a term resembling guilt appear. Given that the corpus of malu cases includes many embarrassment-like events but no guilt-like events, the absence of labels for embarrassment and guilt allows for the drawing of inferences regarding the relationship between each of these emotions and shame.

It appears that embarrassment is a close cousin of shame. Presumably, the similarities between embarrassment and shame make it easy to subsume the former within the latter, reducing the utility of a distinct term for embarrassment - indeed, even in English-speaking societies, where the

${ }^{17}$ Despite the existence of a lexical label for the concept 'emotion,' Bengkulu participants interpreted the task of identifying emotion terms more broadly than did English speakers (cf. Heider, 1991). Words such as 'low,' 'disgraced,' etc., deemed within the domain of emotion terms by Bengkulu participants, require a preface such as "to feel _" in order to be recognized as emotion-like by English speakers (an equivalent preface exists in Bengkulu, but was not consistently employed by participants). Other terms, such as 'sneer' or 'taunt,' which identify actions rather than feeling states, were described by Bengkulu participants as 'full of emotion,' and thus, in their culturally constructed semantic domain, closely associated with true emotions. 


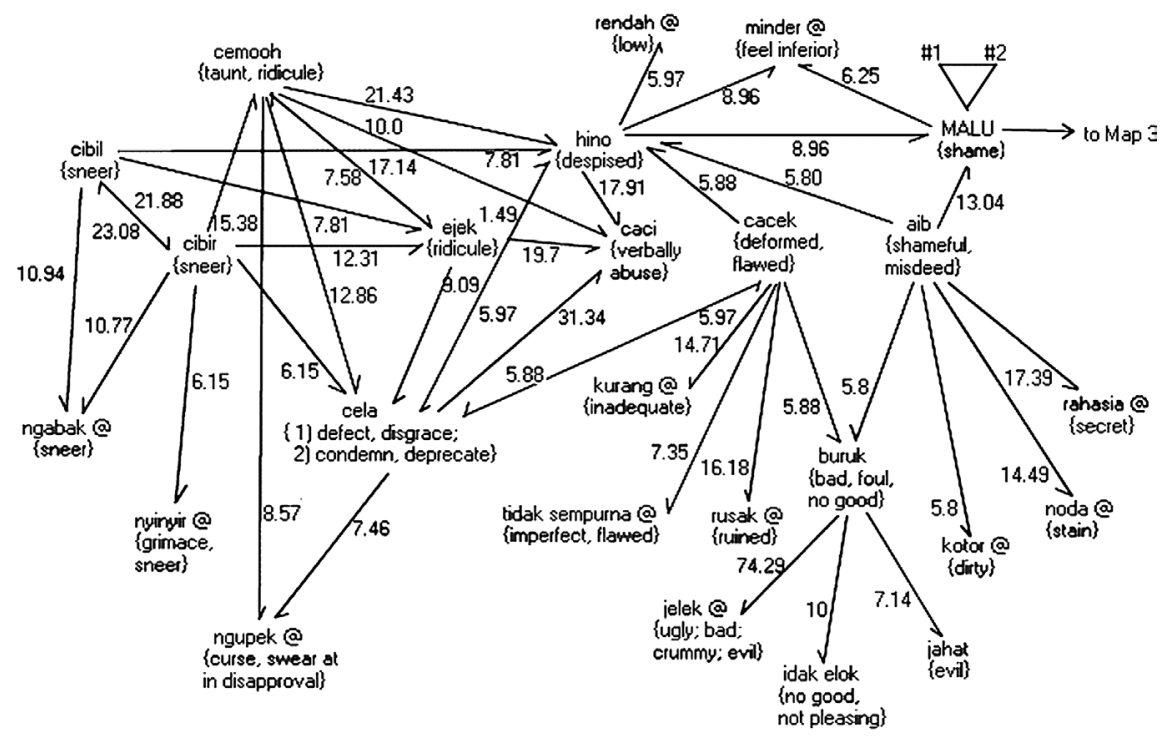

\footnotetext{
\#1 -. Ke mano awak pacak nyuruk muko iko? -> MALLU = 85.51

Where, oh where can I hide my face?\} 〈-MALU $=10.94 ; \cdot>\$ 2=3.13$

\#2 -- Rasonyo idak bekepalo lagi!

\{lt feels like I don't have a head! $\} \quad<-M A L U=1.56$
}

Map 2. The classical shame aspect of the semantic domain of 'malu' in Kota Bengkulu Malay.

$\mathrm{N}=70$. Numbers indicate the percentage of respondents who provided the term the end of the arrow as a synonym for the target term. Minimum for inclusion in map $=5.5$ (summed in the event of bidirectionality). @ = term not given as a prompt.

distinction is explicitly made, it is only recently that researchers have defeated the long-standing theoretical position that embarrassment and shame are the same emotion (reviewed in Tangney, 1999; see also Sabini, Garvey \& Hall, 2001). In contrast, guilt and shame have far less intrinsic similarity. In cultures such as Bengkulu that do not attend to guilt and do not rely on this emotion as an important means of regulating social behavior, guilt-like events (to the extent that they even occur - a question which I was unable to resolve) are in no way associated with shame and closely related emotions.

While Map 2 illustrates a cluster of concepts associated with malu that are largely consistent with the English language notion of 'shame,' Map 


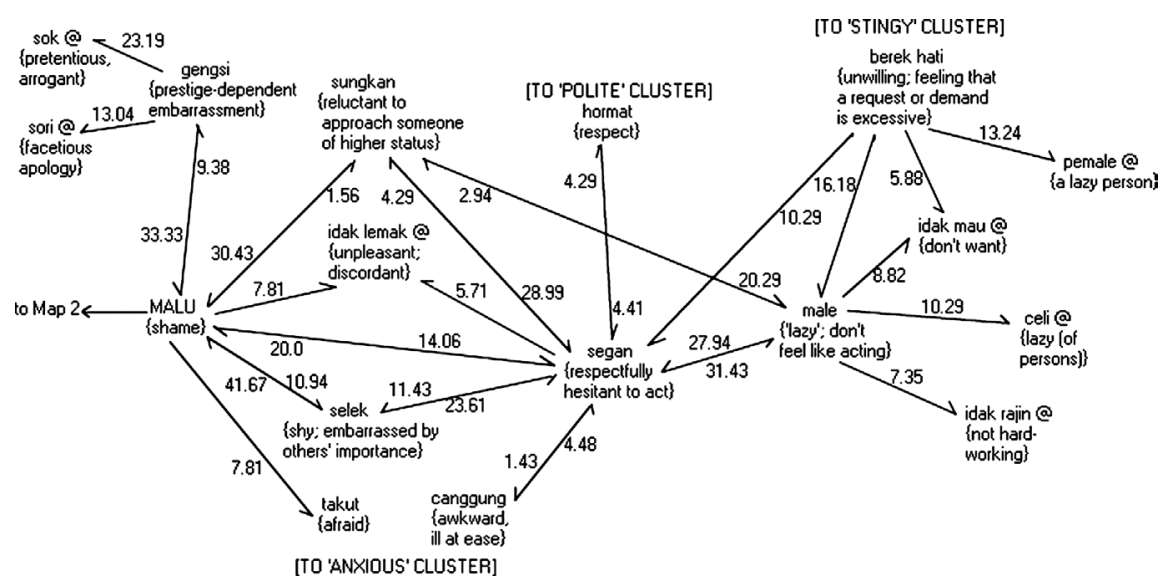

Map 3. The subordinance aspect of the semantic domain of 'malu' in Kota Bengkulu Malay.

$\mathrm{N}=70$. Numbers indicate the percentage of respondents who provided the term at the end of the arrow as a synonym for the target term. Minimum for inclusion in map $=5.5$ (summed in the event of bidirectionality). @ = term not given as a prompt.

3 illustrates a second cluster that, though also strongly linked to malu, may at first seem alien to English speakers. A clear theme runs through this highly interconnected cluster, namely a feeling of timidity, shyness, or hesitation (cf. Fontaine et al., 2002). While such shyness can be elicited by social equals with whom one is simply unfamiliar (as evidenced by many of the malu cases that fit into the shyness category), a prototypical eliciting condition is the presence of a social superior. As underlined by the generic term 'unpleasant,' this is an aversive experience, the anxious feeling felt during interactions with someone who is more powerful than oneself; though not shown, an additional cluster, revolving around clearly negative emotions, is linked via a connection between malu and 'fear' and between segan and 'awkward, ill at ease' (cf. Fontaine et al., 2002; Shaver et al., 2001). However, while the segan cluster is negatively hedonically valenced, it has positive moral value, being linked to terms concerning respect and politeness. The latter connections suggest that the core experience at issue here is not simply unadulterated social fear or intimidation; rather, a key facet is the appropriate recognition of one's subordinate position in a hierarchy (cf. Goddard, 1997; Keeler, 1983; Menon \& Shweder, 1994; Rozin, 2003). 
The prominence of shyness and, more significantly, respectful subordinance in the map of malu synonyms is consistent with the frequencies with which these two categories appear in the corpus of Bengkulu shame events. Given the absence of both categories in the Californian data, this raises the question as to the centrality of these aspects in the underlying panhuman emotion. It is possible that this pattern is akin to that involving guilt in California, namely that there is little intrinsic connection between shame and feelings of hesitation and subordinance, but, because these emotions play overlapping roles in social behavior in Bengkulu, informants associate the latter with the former. Recall, however, that both a) informants' explicit statements regarding subjective experience and outcome behavior, and b) my own observations regarding the latter support the contention that shyness and subordinance are fundamentally similar to, and perhaps part and parcel of, malu. Furthermore, although apparently not sufficiently prominent in either contemporary Californian experience or discourse to appear in the corpus of shame events and the synonym map, the English language nevertheless contains hints of (perhaps previous) associations between shame and subordinance. For example, the Oxford Thesaurus (Urdang, 1992:463-4) lists 'humility,' 'diffidence,' and 'timidity' as synonyms for the noun form of 'shame,' 'put down' and 'bring down' as synonyms for the verb form of 'shame,' and 'surpass,' 'eclipse,' 'outclass,' and 'overshadow' as synonyms for 'to put to shame.' If, as suggested earlier, contemporary Western settings constitute a poor starting point for the investigation of panhuman shame due to the overshadowing effects of guilt, then, across the world's cultures, the lack of subordinance associations characteristic of the Californian data is likely to be the exception rather than the rule.

Although relevant systematic data on shame have yet to be collected using a broad sample of cultures, ethnographers' accounts provide preliminary grounds for concluding that subordinance and shyness play important roles in the experience of shame in a number of non-Western settings. Describing emotions and social relations among the Bedouin of Egypt, Abu-Lughod notes:

[The concept of] hasham involves both feelings of shame in the company of the more powerful and the acts of deference that arise from these feelings... The experience is one of discomfort, linked to feelings of shyness, embarrassment, 
or shame... (1986:108)

... two other words are used almost interchangeably with the phrase "he is ashamed/shy in front of": "he is afraid of" (ykhaf min) and "he respects" (yihtaram)... Hasham, then, in its manifestation as emotional discomfort or shame, is that which motivates avoidance of the more powerful, and in its manifestation as the acts of modesty prompted by these feelings, it is the protective self-masking that occurs when exposure to the more powerful is unavoidable. (1986:112)

More broadly, discussing emotions among the Newar of Nepal, Parish notes

The English emotion term "shame" seems peculiar in cross-cultural perspective, because it does not seem to be semantically and socially organized in terms of conceptual links with "timidity," "fear-fright," and "respect" in the way that the emotion terms often translated by the English word "shame" generally do. (1991:332)

The ancient Greek goddess Aidos personified 'modesty, respect, and shame' (Flexner, 1987); the Ilongot (Aboriginal Phillipines) word betang can be glossed as 'shame, timidity, embarrassment, awe, obedience, and respect,' (Rosaldo, 1983), the Kanuri (Nigeria) word nungu connotes 'shame, avoidance, and respect' (Cohen, 1971), the Maori (Aboriginal New Zealand) word whakama can be glossed as 'shame, embarrassment, shyness, respect, deference, or to suffer in comparison with another' (Sachdev, 1990), and both the Pintupi (Aboriginal Australia) word kunta (Myers, 1979) and the Javanese term isin (Al Jallad, 2002; Geertz, 1959) can be translated as 'shame, embarrassment, shyness, and respect.' Among the Mombasa Swahili (East Africa), highly prestigious individuals elicit a complex blend of 'shame,' 'fear,' and 'respect' (Swartz, 1991). Lastly, consistent with the conclusion that the panhuman emotion shame is intimately concerned with questions of subordinance and shyness, in their cross-cultural study of university students, Wallbott and Scherer (1995) found that participants from highly stratified societies were more likely to provide shame events that had many of the hallmark features of this emotion than were participants from less stratified societies. Also in keeping with the salience of subordinance independent of personal failure, individuals from stratified societies were less likely to view shame events as immoral (see also Menon \& Shweder, 1994; Rozin, 2003). 
In sum, while the association between shame and failure is almost certainly universal, linkages between shame and guilt may reflect parochial cultural factors rather than panhuman psychology. Furthermore, despite the backgrounding of this connection in the West, in many cultures there is a substantial association between shame and subordinance. These findings provide support for aspects of a number of existing evolutionary approaches to shame. Because I will seek to integrate and build on these ideas, before turning to them it is important to first consider the theoretical context within which evolutionary approaches to emotion should be evaluated.

\section{Evolutionary Perspectives on Shame}

\section{The Evolutionary Psychology of Emotions}

Most contemporary scholars agree that human emotions, or at least some core subset thereof, are the product of evolution. Nevertheless, explicitly evolutionary explanations of specific emotions constitute only a small fraction of psychological research, and many of these accounts are relatively undisciplined. The most compelling evolutionary account is one that offers both ultimate and phylogenetic explanations. Ultimate explanations are descriptions of how the given trait would have increased biological fitness in the environments in which the trait evolved; phylogenetic explanations are those which trace the evolutionary history of the trait (Tinbergen, 1963).

Darwin, who foresaw the implications of evolutionary theory for psychology (1872a), pioneered the evolutionary study of emotions (1872b). However, reflecting the rationalist biases of his time, in contrast to his own core tenets of adaptationism, Darwin explained human emotions primarily in vestigial terms. For Darwin, the only ultimate explanations that are appropriate for emotions are thus those which describe the utility of these traits for prehuman species. However, there are only three conditions under which ancestral traits are preserved, namely if a) the trait is not subject to natural selection by virtue of the fact that it does not entail either costs or benefits to the holder, b) the trait maintains its ultimate function across descendant species, or c) the trait is an integral part of some newer adaptation. Emotions profoundly shape human behavior in such crucial domains as social conflict, alliance formation, mating, and 
parenting, hence it is untenable to assume that they have not been subject to natural selection. Accordingly, all universal human emotions must be amenable to one of two types of ultimate explanation: either the emotion performs the same function in humans that it performed in ancestral species (and that it continues to perform in related species), or the emotion performs one or more novel functions in humans, functions derived from, but different than, that performed by its precursor in ancestral species.

There are important reasons for considering the phylogeny of an emotion even if vestigilism is abandoned. Because natural selection can only operate through the gradual modification of existing forms, the history of a trait will often be an important determinant of the resulting design. Accordingly, not all possible ultimate explanations are plausible, since some will be inconsistent with the species' phylogeny. A key step in establishing the phylogeny of a trait is to understand which aspects of the feature are ancestral (and hence will appear as homologies in related species) and which aspects are derived (and hence require ultimate explanations premised on circumstances unique to the given species). Moreover, Darwinism demands that ultimate explanations also be provided for the intermediate stages between the ancestral form and the extant derived trait - the gradual nature of natural selection means that it is not sufficient to point to an ancestral trait as the origin for the given feature without explaining 'how we got here from there.' With these considerations in mind, it is possible to evaluate existing evolutionary perspectives on shame.

\section{Existing Evolutionary Perspectives on Shame}

The renaissance of modern research on shame began in clinical settings (Lewis, 1971, 1987). While many contributors to the resulting literature have usefully elucidated key features of the emotion, in general, shame is construed as a problem or source of pathology (cf. Tangney, 1999; Tangney \& Dearing, 2002), an approach which begs the evolutionary question of why humans should universally experience this emotion. To the extent that they address evolutionary issues at all, many authors in this tradition fail to command the relevant premises. For example, Tangney et al. state 
The adaptive functions of shame are somewhat less clear [than those of guilt]. There are numerous indications that shame may promote less helpful behavior in many instances (e.g., withdrawal, anger, externalization of blame), at least among adults... Our hunch is that shame is, in some sense, a more primitive emotion that served adaptive functions especially at earlier stages of development (either in earlier stages of evolution or individual development). (1996:1267; bracketed material added)

Tangney et al. confuse the promotion of harmonious social relationships in contemporary Western environments with fitness enhancement in ancestral environments. Withdrawal may often be a fitness enhancing tactic, particularly in face-to-face communities of the kind that likely prevailed for most of human history, and the same may be true of anger, blaming, and aggression (Fessler, 2001). The authors also commit the same error as Darwin, supposing that an emotion which profoundly influences behavior in a wide variety of fitness-relevant domains can be explained in vestigial terms. A similar error occurs in arguing that a trait with significant impact on adults can be explained as the remnants of a mechanism that is only adaptive earlier in ontogeny.

Schore (1998) offers an ultimate explanation of shame focusing on the utility of passive disengagement from unfavorable environmental stimuli during infancy. However, this position is premised on an erroneous equation of shame with tonic immobility. Although intense shame may indeed inhibit action, shame events involve highly stereotypic behaviors that in no way emulate death. Moreover, given the substantial influence of shame on adult behavior, it is implausible to presume that the adult emotion is merely the lingering remainder of a mechanism that enhanced fitness early in life.

Tomkins (1987) and Nathanson (1992) argue that the ultimate function of shame is to cut off interest, enjoyment, and similar positive affects. However, shame is a complex trait involving coordinated display behavior and coherent action tendencies. If the function of shame is to cut off positive affect, it is unclear why any display is necessary, or why avoidance of social scrutiny should follow. Defenders of the cut-off theory might respond that this mechanism was derived from an earlier trait that served a different purpose, hence the display and action tendencies of shame are explicable as ancestral features that have been preserved because they are inseparable from the trait. However, this would suppose that the need to 
cut off positive affect is phylogenetically recent. Given that all mammals seem capable of positive affect, this is not a tenable presumption.

In contrast to the perspectives described above, often working independently of one another, a number of investigators have formulated overlapping evolutionary explanations of shame that take fuller account of the emotion's antecedents, display behaviors, and action tendencies. Important initial insights are the recognitions that a) the shame display has an antithesis, namely the pride display, and b) the core components of these two displays (direction of gaze, erectness of posture, and gait) are components of displays employed by nonhuman primates (and other mammals) during the negotiation or affirmation of relative rank (Fessler, 1999; Gilbert, 1989, 1992; Keltner \& Harker, 1998; Weisfeld, 1999; Weisfeld, 1997). The averted gaze, shrinking posture, and bent-kneed gait associated with shame are elements in the appeasement displays of many nonhuman primates. Appeasement displays signal to dominant individuals that the actor accepts a subordinate position in the dominance hierarchy. By signaling such acceptance, the subordinate attempts to dissuade the dominant from aggressing, as it is in the dominant's interests to avoid incurring the costs of conflict if his or her superiority is already acknowledged.

Keltner and colleagues (Keltner \& Buswell, 1997; Keltner \& Harker, 1998) argue that the utility of the appeasement function is preserved in shame since, in humans, those who are unable to appease others following transgressions of the moral code risk becoming the target of collective aggression or exclusion. ${ }^{18}$ In support of this thesis, Keltner and associates (Keltner \& Harker, 1998; Keltner et al., 1997) review a variety of evidence indicating that displaying shame (and acting accordingly) can enhance reconciliation and social reincorporation following moral transgressions (see also De Jong, Peters, De Cremer \& Vranken, 2002).

Turning from the signalling aspects of display behavior to the motivational facet of the emotion, Weisfeld $(1997,1999)$ and myself (Fessler, 1999, 2001) similarly argue for phylogenetic continuity between shame and the rank-related emotions of nonhuman primates. Stressing the consequences

\footnotetext{
${ }^{18}$ Keltner and colleagues (Keltner, 1995; Keltner \& Buswell, 1997) have documented the distinct nature of the embarrassment display, and both Keltner et al. and Leary and Meadows (1991) have argued for a similar phylogeny and similar appeasement function to that of shame.
} 
for behavior of shame's negative hedonic valence and pride's positive valence, both argue that these two emotions motivate efforts to attain high rank, as it is aversive to occupy a subordinate position in a hierarchy and rewarding to occupy a dominant position. In all social animals rank is associated with access to the physical and social resources that translate into biological fitness, hence natural selection crafted a pair of emotions which motivate the pursuit of high rank. Because this fundamental source of selective pressure remained largely unchanged over hominid evolution, humans possess the same core motivational structure as other primates.

Emphasizing the subjective sensations (feeling small, inferior, inadequate, etc.) and action tendencies (desire to flee, hide, avoid social contact, etc.) of shame, together with his associates, Gilbert (Gilbert, 1992, 1997; Gilbert \& McGuire, 1998; Gilbert, Price \& Allan, 1995) has been one of the principal proponents of a phylogenetic linkage between shame and emotions attending subordinate status in nonhuman primates. However, following Barkow (1975, 1989), Gilbert makes the important observation that whereas in nonhuman primate groups social position is largely determined by fighting ability, in human groups social position is often determined by the possession of socially valued personal, material, and social attributes; this is especially true in the small-scale acephalous groups which are likely to have been typical of most human societies for most of our species' existence. Hence, whereas in nonhuman primates it is often the ability to displace and intimidate others that translates into biological fitness, in ancestral humans fitness was probably importantly contingent on the ability to attract positive social attention, a variable which Gilbert terms Social Attention Holding Power (SAHP). Shame, Gilbert argues, is an adaptation designed to maximize SAHP by marking decreases therein and assigning negative hedonic valence to such changes. In this view, in the course of hominid evolution an existing rank-related emotion was redirected in accord with the shift from dominance to prestige as the basis of rank. The functional significance of this emotion then expanded, since the grounds for determining social status depend upon the domain in which evaluation is occurring - unlike a simple motive for dominance, the desire to be thought well of by others can motivate attempts to excel on a wide variety of criteria in a diverse range of contexts (Gilbert \& McGuire, 1998). 
In contrast to Keltner and colleagues, Gilbert and McGuire (1998:114) (see also Gilbert, 2001) assert that both the shame display (specifically gaze avoidance) and shame's outcome behaviors (hiding, inhibition of further action) are dysfunctional in humans, since, the authors claim, they reduce rather than enhance social desirability. The authors argue that, because the display and outcome behaviors are intrinsic to the emotion, we are saddled with the appeasement-related features of shame's evolutionary precursors even though shame's utility derives from its ability to mark the current state as one of social undesirability rather than subordinance - in short, both the display-as-signal and the stereotyped action tendencies are vestigial traits that are retained because they are inexorably linked to the motivational component, an adaptation that itself has shifted focus.

While concurring with Gilbert and colleagues that prestige has largely replaced dominance as the foundation for rank in humans, Greenwald and Harder (1998:235) note that retreating behaviors can nonetheless be adaptive in the context of loss of status, since the avoidance of further scrutiny can preclude additional decreases in prestige. Likewise, D'Arms (1996:76) suggests that it is often adaptive to avoid or leave a social milieu or domain in which one lacks the attributes necessary for successful performance.

Focusing again on the motivational aspects of the emotion, several investigators (Fessler, 1999; Gilbert, 1997; Gilbert \& McGuire, 1998; Greenwald \& Harder, 1998) note that, because inclusion in social groups is a key determinant of fitness in humans, and social disapproval can lead to ostracism, both the anticipation of shame and the learning that follows aversive shame events enhance fitness by prompting conformity to prevailing standards for behavior. Greenwald and Harder (1998:230) argue that inclusion in social groups is a determinant of fitness in part because of the benefits of reciprocal relationships that form within such groups. Groups are marked by a wide variety of norms and conventions, hence it is important to conform to such behaviors in order to signal one's membership to potential reciprocating partners; shame makes nonconformity aversive, thus promoting membership and hence access to reciprocating partners. 


\section{A Synthesis of Evolutionary Perspectives in Light of the Gross-Cultural Data}

How do the cross-cultural data bear on the evolutionary theories summarized above? Granted, definitive evaluation is not yet possible, as the experience of shame has only been examined in any detail in a small fraction of the world's cultures. Nevertheless, because Bengkulu seems to have much in common with many other collectivist cultures, while California seems to share numerous features with other individualistic cultures, it is not unreasonable to take an initial step toward evaluating existing evolutionary perspectives on shame by combining material from my studies of these two cultures with gleanings from the cross-cultural literature. The first and foremost conclusion supported by such an evaluation is that, given the cross-cultural robusticity of the classical shame configuration, there are strong grounds for supposing that we possess an evolved psychological mechanism that makes us exquisitely sensitive to the extent to which others view us unfavorably. As illustrated by many of the terms linked to malu in Map 2, the salient aspect of such negative evaluation is the likelihood of ensuing rejection.

\section{Defection in Cooperative Relationships}

Consistent with the goal of avoiding rejection, both the Californian and the Bengkulu data include stories in which an individual's actions place a valuable relationship at risk, leading to a profoundly aversive emotion once the other party learns of the misdeed or failing. For example, in California a middle-aged woman reported feeling shame when her husband came home unexpectedly and found her smoking marijuana; he was a retired police officer and she knew that he was strongly opposed to drug use. In Bengkulu a young man felt malu when a cousin discovered that he had embezzled money from their business. Revisiting the data sets, $13.7 \%$ of Californian classical shame stories and $46.5 \%$ of mixed shame/guilt stories involve defections in cooperative relationships; the same is true of $8.72 \%$ of the Bengkulu classical shame events. Sensitivity to negative evaluation by valued partners likely motivates learning from such situations, and the desire to avoid similar experiences likely reduces the temptation to trade the long-term benefits of reciprocity for the lesser short-term benefits of defection (Bowles \& Gintis, 2002). Moreover, both the importance 
of publicity in many of the stories and the desire to hide from public scrutiny, features of shame that have been noted by many psychologists and ethnographers (Barrett, 1995; Boehm, 1984; Gregor, 1977; Mikulincer \& Florian, 1997; Sachdev, 1990; Smith et al., 2002; Tangney et al., 1996; van Beek, 1994), suggest that the functional significance of this emotion extends beyond the immediate relationship. If an individual has performed poorly in one relationship, publicizing this fact reduces the individual's prospects for establishing additional relationships, since others will downgrade the individual as a potential partner. Experiencing greater discomfort in accord with greater publicity can thus be construed as an adaptive subjective representation of the increased damage done to present and future relationships.

\section{Prestige Competition}

While the value of reciprocal relationships explains the utility of some instances of shame, a number of shame events involve failings in competitive rather than cooperative contexts. For example, in California a young soldier reported feeling shame upon being beaten by a rival in a sit-up contest during basic training; in Bengkulu an adult man felt malu when it became clear that he was the worst drummer in the village (drumming is a public activity in which many men participate). Wicker, Payne, and Morgan's (1983) Texan participants reported that shame events are associated with a desire to compete with others. Here Gilbert's point that prestige is a proxy for access to resources is useful. Failure to effectively compete according to local criteria for success leads to a reduction in prestige, with corresponding decreases in access to fitness-determining opportunities (Barkow, 1975, 1989; Greenwald \& Harder, 1998). Because prestige is bestowed or withdrawn by the members of the group at large, the more publicity associated with an individual's failure, the greater the fitness costs incurred; it is therefore adaptive to experience discomfort in proportion to exposure. Prestige is always relative, hence shame of this sort should be associated with failures on criteria that can be used to rank competitors in a given arena. Revisiting the data with an eye toward this feature, $6.16 \%$ of the Californian classical shame stories and $12.8 \%$ of the equivalent Bengkulu 
cases can be considered prestige-related failures. ${ }^{19}$ Correspondingly, as illustrated in Map 3, malu is linked to a cluster of three terms that directly concern prestige competition: 'prestige-dependent shame/embarrassment,' 'facetious apology' (snubbing behavior stemming from prestige disparities), and 'arrogant' (the character trait associated with snubbing).

\section{Conformity}

While defection and prestige competition usefully explain some classical shame events, in both California and Bengkulu over three-quarters of these cases do not involve cheating a partner or failing on criteria amenable to use in ranking. Rather, most classical shame events simply center on failing to meet a minimum standard for social acceptability. For example, a boy in Bengkulu felt malu because he had reached puberty without having been circumcised. Among adolescent boys in Bengkulu, prestige is obtained through athletic or musical ability, acts of daring, or successful attraction of desirable adolescent girls. Having been circumcised does not enhance an adolescent's prestige; rather, this is a minimum requirement for acceptability among adolescent boys. In cases such as this, shame stems not from being beaten by one's rivals in a competitive arena, but rather from failing to conform, failing to be just like, as opposed to better than, the other members of one's group. ${ }^{20}$ Gilbert's general concept of

${ }^{19}$ The Bengkulu data set does not include many references to malu-as-a-consequenceof-defeat which occurred during volleyball games, as these statements were clearly playful in nature (see Fessler, 1995). Nonetheless, the fact that such utterances were common is congruent with the argument made here regarding prestige competition. The low percentage of prestige cases in California could reflect either the rarity of prestige-failure shame or the more peripheral status of such events in the cultural schema of shame. Two research assistants therefore asked 60 native-born English-speaking Californians "Can you think of a time when you or someone you know felt shame as a result of losing some sort of competition, contest, or fight, or otherwise performing poorly compared to other people? If so, describe the event; you may disguise the identity of the person if you wish to do so." 33 young men and 24 young women responded. 26 participants provided clear prestige-failure shame cases, 14 stated that they could not think of such a case, and 13 provided cases of other types of shame. The fact that nearly half of participants recounted instances of competitive prestige-failure shame when prompted to do so suggests that the this is indeed part of the shame experience in California, albeit perhaps not a central feature thereof.

${ }^{20}$ In Bengkulu, as in many other cultures, the concept of 'face' (likely derived from the role of facial direction in the shame display) addresses the question of minimum social 
Social Attention Holding Power encompasses events such as these, since it is clear that actors suffer from reduced social acceptability, and hence are at risk of exclusion from social groups (Gilbert, 1997, 1998; Gilbert \& McGuire, 1998). However, while useful, the concept of SAHP fails to specify why observers should care about an individual's failure to meet (often arbitrary) minimum social standards. Attention and decision making are finite cognitive capacities. Attending to another's behavior and adjusting one's interactions occupies these capacities and is thus costly. An explanation must therefore be provided as to why people discriminate between conformists and nonconformists.

Greenwald and Harder point out that conformity to group standards signals group membership, thereby increasing access to the reciprocal relationships that form within the group. While this explanation is on the right track, it begs the question of why such relationships are more commonly formed within the group. The key here is that individuals who adhere to the same standards for behavior can more readily predict one another's actions. Increased predictability is valuable because it facilitates coordination across individuals, and coordination is crucial to cooperation (cf. McElreath, Boyd \& Richerson, 2003). Observers thus attend to an individual's degree of conformity to a wide variety of social standards because such conformity is informative not merely about the individual's group membership but, more profoundly, about the individual's future predictability. The individual's reputation as a conformist is thus a valuable asset. The greater the number of people who know of one's failure to conform, the larger the number of prospective cooperative ventures from which one may be excluded as a result. It is this which likely accounts for the highly aversive nature of an awareness that others know that one has failed to meet a minimum standard for social acceptability. ${ }^{21}$

acceptability. While it is possible to lose face, and to seek to regain it, unlike prestige, individuals cannot accrue increasing amounts of face - the standards for social acceptability constitute a threshold that must be met, not a ladder with multiple rungs.

${ }^{21}$ An alternative explanation of the source of selective pressure favoring both conformity and attendance to others' actions centers on the ability of punishment practices to stabilize a wide variety of social behaviors (Boyd \& Richerson, 1992). While fundamentally different, these two explanations are not mutually exclusive. 


\section{Subordinance}

Although classical shame events revolve around failure to live up to cultural standards, the corpus of Bengkulu shame cases, the Bengkulu synonym results, and the anecdotal material from the ethnographic literature all support the claim that involuntary subordination (Gilbert, 1992, 1997) suffices to produce shame in the absence of any distinct failure (cf. Gilbert, 1998:11). For example, many of the Bengkulu subordinance events involve young individuals interacting with older individuals. Being young does not constitute a violation of a reciprocal relationship, it cannot be construed as failure in an open competition for prestige, and it does not involve norm violations. Correspondingly, from a functional perspective, youth is not an index of an individual's poor future potential or unpredictability. It is thus difficult to explain this type of shame with reference to the social consequences of failure.

Humans clearly differ from other primates in the degree to which prestige has replaced coercive power as the foundation for rank. However, it is important not to overestimate the extent of this change. Dominance remains an important part of human affairs, and likely has throughout our species' history. While most extant or historical hunter-gatherer societies exhibit a relatively acephalous social organization and an egalitarian ethos, it is nevertheless common to find power inequalities based on age, gender, physical strength, and number of kin, among other factors (see Kelly, 1995). The same was surely true of ancestral human groups, and this will have influenced the evolution of human motivational systems. Simple subordinance shame, the ancestral trait evident in other primates, has been preserved in the repertoire of human emotions because the selective force of dominance ranking, though attenuated, has never disappeared.

\section{The Utility of Appeasement Displays in Different Forms of Shame}

The recognition that shame can mark a) simple subordinance, b) failure to uphold reciprocal relationships, c) failure in prestige competitions, and d) failure to conform to elementary standards sheds light on the conflicting claims regarding the utility of shame display behaviors. First, in human subordinance events appeasement signals retain their ancestral function, namely to reduce aggression from a more powerful individual. Second, Keltner and associate's claim that displaying shame (or embarrassment) 
can mitigate the costs of failure most likely pertains both to defections in reciprocal relationships and to failure to conform to norms. Appeasement displays directed toward a partner who has been wronged can decrease the likelihood of aggression by signaling that the actor recognizes a shift in power within the dyad as a consequence of the failure - understanding that the dynamic of the relationship has changed, the partner may choose to extract additional value from the individual rather than aggress, thus leading to the preservation of the relationship. Similarly, appeasement displays associated with failure to conform to social standards signal that the individual recognizes the importance of the given standard (Leary, Landel \& Patton, 1996). Actors who are unconcerned with cultural standards and social evaluation ('thick eared,' as the Bengkulu felicitously describe them) are dangerously unpredictable (Cohen, 1971; Gilbert \& McGuire, 1998). Such individuals are excluded from cooperative ventures, ostracized, or, as occurred in an extreme case in Bengkulu, assaulted by the community. Since perfect conformity is often unattainable, individuals thus benefit from the ability to unambiguously communicate that, despite having faltered, they both understand and strive to uphold the relevant social standards, i.e., they are not 'thick eared' and should not be treated as such. However, in contrast to the utility of appeasement displays in cases of subordinance, defection, or nonconformity, as Gilbert and McGuire point out, such signals are often counterproductive in prestige competitions. The damage to prestige entailed by defeat is magnified by actions that inform an audience that the competitor assesses him- or herself as inferior. We respect those who acknowledge that they have been bested while still conveying the promise of future excellence, but we scorn losers who grovel or slink away, for this indicates that they lack any hope of future glory. The utility of the shame display thus importantly depends on the context in which it occurs. Presumably, in comparison with the fitness benefits of displaying appeasement in cases of subordinance, defection, or norm violation, the costs of the shame display in situations of prestige defeat have not sufficed to eliminate this feature of the trait.

\section{Shame, Admiration, and the Difference Between Dominance and Prestige}

Ranking on the basis of prestige retains the competitive element intrinsic to dominance ranking, and, just as in dominance competitions, defeat by 
a rival in prestige competitions elicits shame. However, prestige differs in important ways from dominance, and these differences are reflected in human emotions. The greater the disparity in dominance between two individuals, the greater the threat posed by the higher-ranking individual, and hence the greater the need for the lower-ranking individual to avoid interaction when possible, and evince appeasement behavior when interaction occurs. In contrast, in the case of prestige disparities, lowranking individuals are actually attracted to high-ranking individuals, often seeking to interact with them as much as possible. Instead of eliciting a negative emotion linked to an appeasement display, exposure to an individual of substantially higher prestige typically elicits admiration, a positive emotion associated with affiliation displays (Henrich \& Gil-White, 2001; Smith, 2000). These differences are understandable in terms of the costs and benefits of interacting with prestigious versus powerful people (Henrich \& Gil-White, 2001). Prestige is garnered through success in socially valued activities. Prestigious individuals thus constitute models of techniques with proven utility in the local context, techniques that can be acquired through imitation. ${ }^{22}$ In contrast, particularly in small-scale societies like those which likely characterized ancestral human populations, power is a function of features, such as strength and number of kin, that are intrinsic to the individual. Copying a prestigious individual can lead to success, hence it pays to be attracted to, and to want to learn from and be similar to, such people. Coercive power cannot be acquired so easily, hence there are few benefits, and many potential costs, to interacting with powerful individuals (Henrich \& Gil-White, 2001). These differences explain why, despite the substitution of prestige for dominance as the basis for ranking in many human arenas, shame does not play the same role in prestige-based interactions that it does in dominance-based interactions. It is only in direct prestige competition, a situation fully analogous to dominance competition, that lower prestige individuals experience shame, the emotion of subordinance.

\footnotetext{
${ }^{22}$ Substantial prestige disparities can also elicit envy, the antithesis of admiration (Fessler, 1999; Gilbert, 1992; Schoeck, 1969; Smith, 2000). In this case, instead of serving as a model for imitation, the high-ranking individual is seen as a monopolizer of resources in a zero-sum game, a framing within which hostility, rather than affection, has adaptive utility (Fessler \& Haley, 2003).
} 


\section{Reconstructing the Evolution of Shame}

Subordinance shame, a homology of the emotion that likely motivates appeasement displays in nonhuman primates, plausibly constitutes the ancestral aspect of human shame, while shame in contexts of defection, prestige failure, and nonconformity presumably constitute the derived, uniquely human aspects of this trait. The event sequence characteristic of derived forms of shame can be described schematically as follows (Fessler, 1999; Fischer \& Tangney, 1995; cf. Goddard, 1997):

1) The individual fails to perform adequately on some shared standard for behavior;

2) The individual is aware of their failure;

3) Others are aware of the individual's failure;

4) The individual is aware that others are aware of the failure (or the individual anticipates or imagines awareness by others);

5) Others display negative evaluations of the individual (or the individual anticipates or imagines such reactions);

6) The individual experiences shame.

In contrast, the ancestral subordinance emotion is far simpler:

1) The individual evaluates an other as dominant;

2) The individual interacts with the other;

3) The individual experiences shame.

Note that the derived forms of shame are premised on the capacity to manipulate a theory of mind, as these forms are contingent on the ability to contemplate others' awareness of, and reactions to, one's actions - in Darwin's words, it is "the thinking [about] what others think of us" which evokes the emotion (1872b:325) (see also Gilbert, 1992:228; Scheff, 1988). In contrast, the ancestral form of shame in no way necessitates the ability to think about others' assessments of oneself, but rather is contingent merely on the capacity to assess relative position in a social hierarchy. While the ability to employ a theory of mind is either extremely limited or absent in nonhuman primates (Heyes, 1998; Povinelli \& Bering, 2002), even relatively simple vertebrates are adept at assessing relative social position.

The centrality of issues of public scrutiny and norm violation to a majority of the shame events in California and Bengkulu suggest that, while shame can operate in many ways, its most important function is to motivate conformity in the service of furthering social acceptance. The 
development of the capacity for a theory of mind was clearly an important factor in the evolution of shame. However, this alone does not explain how an emotion motivating conformity evolved from a rank-related emotion. The role of shame in prestige competition provides the intermediate step demanded by Darwinian gradualism.

It is likely that, with the evolution of behaviors such as food sharing, skill became a key determinant of an individual's value to others (Kaplan, Hill, Lancaster \& Hurtado, 2000). At the same time, the development of complex cooperation likely also allowed subordinates to coordinate their actions in order to reduce the coercive capacities of dominants (Boehm, 1999). Together, these factors led to a reduction in the importance of dominance and an increase in the importance of prestige. Although the grounds for social organization shifted somewhat, the essential phenomenon of ranking remained, as did the core relationship between rank and access to resources. These continuities facilitated the modification of the existing rank-related motivational system. However, because, unlike dominance, prestige must be granted by others, as prestige increased in importance, the ability to understand others' assessments of one's worth became crucial to evaluating one's position in the social order. The addition of a theory of mind to ancestral subordinance shame thus created a prestigerelated emotion on top of a dominance-related emotion; phrased in design terms, the more primitive emotion constituted a preadaptation that set the stage for the evolution of a more complex emotion as cognitive capacities increased (see Rozin et al. (1997) and Rozin (1999) for discussion of similar processes in the evolution of disgust).

At the same time that prestige came to partially supplant dominance, increasing returns from inclusion in cooperative ventures generated selective pressure favoring the development of a motivational system leading individuals to behave in ways such that others viewed them as predictable and reliable. The evolving prestige-related shame contained all of the necessary features (attention to shared standards, concern with others' opinions) for such a system. Natural selection therefore modified a fundamentally competitive emotion so that it could also motivate simple conformity - in addition to striving not to be bested by their rivals, individuals now also worked not to fall out of line with the majority. Yet, even as these changes occurred, fundamental power disparities remained. As a result, the 
utility of dominance-relevant emotions, while reduced, did not disappear. Prestige- and conformity-related aspects of shame thus developed in addition to the basic subordinance-related emotion, complementing, but not wholly replacing, this more primitive feature.

\section{Conclusion}

Results from three studies on shame in Southern California reflect both the predominance of guilt in the regulation of social behavior in the West and the cultural hypocognizing of the aversive experience of subordinance, a condition antithetical to the meritocratic values of many Western societies. Because of these culture-specific emphases, data collected in the West may provide an incomplete view of the underlying, species-typical emotional architecture, a limitation that complicates attempts to explore the ultimate functions and phylogeny of shame. Together with previously published ethnographic and cross-cultural psychological work, results from three studies on shame in Bengkulu more clearly reveal multiple facets of shame. Perhaps more than any other emotion, shame, which makes subordinance, prestige failure, and social rejection aversive, reflects the probable evolution of hominid social systems from highly hierarchical structures to more fluid forms of organization. Though differentially masked or elaborated by the diverse cultures of today, shame carries the hallmarks of a motivational system that evolved in bands of hunter-gatherers, groups in which widespread cooperation occurred alongside disparities in power and prestige.

\section{Acknowledgements}

Portions of this research were supported by a National Science Foundation Dissertation Improvement Grant, a Kenneth and Dorothy Hill Foundation Fellowship, a Spencer Memorial Fellowship, and grants from the FulbrightHays Foundation and the University of California. Research was sponsored by the Social Sciences Division of the Indonesian Institute of Sciences. I am grateful to the people of Bengkulu for their hospitality and friendship, and to Jennifer and Erin Fessler for their important contributions to fieldwork. Many colleagues, including Paul Rozin and Klaus Scherer, provided helpful feedback on earlier versions of this work. I am indebted 
to the undergraduate research assistants, too numerous to list, who aided in this enterprise.

\section{REFERENCES}

ABu-Lughod, L.

1986 Veiled sentiments: Honor and poetry in a Bedouin society. Berkeley: University of California Press.

Al JALlaD, N.T.

2002 Shame in English, Arabic, and Favanese: A comparative lexical study. Ph.D. dissertation, Linguistics, University of Delaware.

AL-ANSARI, B.M.

2000 Emotional traits among young male and female Kuwaitis. Zournal of the Social Sciences 28(2), 121-152.

Aunger, R.

1999 Against idealism/contra consensus. Current Anthropology 40(supplement), S93S101.

BABCOCK, M.K. AND J. SABINI

1990 On differentiating embarrassment from shame. European fournal of Social Psychology 20(2), 151-169.

BARKOW, J.H.

1975 Prestige and culture: A biosocial interpretation. Current Anthropology 16(4). 553572.

1989 Darwin, sex, and status: Biological approaches to mind and culture. Toronto: University of Toronto Press.

BARRETT, K.C.

1995 A functionalist approach to shame and guilt. In J.P. Tangney \& K.W. Fischer (Eds.), Self-conscious emotions: The psychology of shame, guilt, embarrassment, and pride (pp. 25-63). New York: Guilford Press.

BARTH, F.

1981 Features of person and society in Swat: Collected essays on Pathans. Boston: Routledge \& K. Paul.

Baumeister, R.F., A.M. Stillwell and T.F. Heatherton

1995 Interpersonal aspects of guilt: Evidence from narrative studies. In J.P. Tangney \& K.W. Fischer (Eds.), Self-conscious emotions: The psychology of shame, guilt, embarrassment, and pride (pp. 255-273). New York: Guilford Press.

BENEDICT, R.

1946 The chrysanthemum and the sword: Patterns of Japanese culture. Boston: Houghton Mifflin company.

BODding, P.O.

1924 A chapter of Santal folklore. Kristiania: A.W. Brøggers boktr.

BOEHM, C.

1984 Blood revenge: The anthropology of feuding in Montenegro and other tribal societies. Lawrence, Kan.: University Press of Kansas. 
1999 Hierarchy in the forest: The evolution of egalitarian behavior. Cambridge, Mass.: Harvard University Press.

Bolyanatz, A.H.

1994 Matriliny and mortuary feasting among the Sursurunga of New Ireland, Papua New Guinea. Ph.D. dissertation, Anthropology, University of California San Diego.

BOWLES, S. AND H. GINTIS

2002 Prosocial emotions. Santa Fe Institute Working Paper \#02-07-028.

BOYD, R. AND P.J. RICHERSON

1992 Punishment allows the evolution of cooperation (or anything else) in sizable groups. Ethology \& Sociobiology 13(3), 171-195.

CoHen, R.

1971 Dominance and defiance: A study of marital instability in an Islamic African society. Washington D.C.: American Anthropological Association.

Cosmides, L. And J. ToObY

2000 Evolutionary psychology and the emotions. In M. Lewis \& J.M. Haviland-Jones (Eds.), Handbook of Emotions (2nd ed., pp. 91-115). New York: Guilford Press.

Creighton, M.R.

1990 Revisiting shame and guilt cultures: A forty-year pilgrimage. Ethos 18(3). 279307.

Crozier, W.R.

1990 Social psychological perspectives on shyness, embarrassment, and shame. In W.R. Crozier (Ed.), Shyness and embarrassment: Perspectives from social psychology (pp. 19-58). New York: Cambridge University Press.

Crystal, D.S., W.G. Parrott, Y. Okazaki and H. Watanabe

2001 Examining relations between shame and personality among university students in the United States and Japan: A developmental perspective. International Fournal of Behavioral Development 25(2), 113-123.

Culshaw, W.J.

1949 Tribal heritage: A study of the Santals. London: Lutterworth Press.

D'ARMs, E.J.

1996 Evolution and the moral sentiments. Ph.D. dissertation, Philosophy, University of Michigan.

DARWIN, C.

1872a On the origin of species by means of natural selection; or, The preservation of favored races in the struggle for life (5th ed.). New York: D. Appleton and Company.

$1872 \mathrm{~b}$ The expression of the emotions in man and animals. London: J. Murray.

De Jong, P.J., M. Peters, D. De Gremer and C. Vranken

2002 Blushing after a moral transgression in a prisoner's dilemma game: Appeasing or revealing? European Fournal of Social Psychology 32(5), 627-644.

Dentan, R.K.

1979 The Semai: A nonviolent people of Malaya (Fieldwork ed.). New York: Holt Rinehart and Winston.

Departemen Pendidikan dan Kebudayaan, R.I.

1990 Kamus besar Bahasa Indonesia (3rd ed.). Jakarta: Balai Pustaka. 
EAST, R.

1939 Akiga's story: The Tiv tribe as seen by one of its members. London: Oxford University Press.

Echols, J.M., H. Shadily, J.T. Collins and J.U. WolfF

1989 An Indonesian-English dictionary (3rd ed.). Ithaca: Cornell University Press.

EID, M. AND E. DIENER

2001 Norms for experiencing emotions in different cultures: Inter- and intranational differences. Zournal of Personality \& Social Psychology 81(5), 869-885.

EPSTEIN, A.L.

1992 In the midst of life: Affect and ideation in the world of the Tolai. Berkeley: University of California Press.

FAJANS, J.

1983 Shame, social action, and the person among the Baining. Ethos 11(3), 166-180.

Ferguson, T.J., H. Stegge and I. Damhuis

1991 Children's understanding of guilt and shame. Child Development 62(4), 827-839.

FESSLER, D.M.T.

1995 A small field with a lot of hornets: An exploration of shame, motivation, and social control. Ph.D. dissertation, Anthropology, University of California, San Diego.

1999 Toward an understanding of the universality of second order emotions. In A.L. Hinton (Ed.), Biocultural approaches to the emotions (pp. 75-116). New York: Cambridge University Press.

2001 Emotions and cost/benefit assessment: The role of shame and self-esteem in risk taking. In R. Selten \& G. Gigerenzer (Eds.), Bounded rationality: The adaptive toolbox. Cambridge, MA: MIT University Press.

2002 Windfall and socially distributed willpower: The psychocultural dynamics of rotating savings and credit associations in a Bengkulu village. Ethos 30(1/2), 25-48.

Fessler, D.M.T. And K.J. Haley

2003 The strategy of affect: Emotions in human cooperation. In P. Hammerstein (Ed.), The genetic and cultural evolution of cooperation (pp. 7-36). Cambridge, MA: MIT Press.

Fischer, K.W. AND J.P. TANGNEY

1995 Self-conscious emotions and the affect revolution: Framework and overview. In K.W. Fischer \& J.P. Tangney (Eds.), Self-conscious emotions: The psychology of shame,

FLEXNER, S.B. guilt, embarrassment, and pride (pp. 3-22). New York: Guilford Press.

1987 The Random House dictionary of the English language (2nd, unabridg ed.). New York: Random House.

Fontaine, J.R.J., Y.H. Poortinga, B. Setiadi and S. Markam

2002 Cognitive structure of emotion terms in Indonesia and The Netherlands. Cognition \& Emotion 16(1), 61-86.

FRANK, R.H.

1988 Passions within reason: The strategic role of the emotions. New York: W.W. Norton \& Co, Inc. 
FRIEDL, E.

1962 Vasilika: A village in modern Greece. New York: Holt Rinehart and Winston.

FriJdA, N.H. AND B. MESQUita

1994 The social roles and functions of emotions. In S. Kitayama \& H.R. Markus (Eds.), Emotion and culture: Empirical studies of mutual influence (pp. 51-87). Washington, DC: American Psychological Association.

GeErTZ, H.

1959 The vocabulary of emotion: A study of Javanese socialization processes. Fournal for the Study of Interpersonal Processes 22(Aug), 225-237.

Gilbert, P.

1989 Human nature and suffering. Hillsdale: L. Erlbaum Associates.

1992 Depression: The evolution of powerlessness. New York: The Guilford Press.

1997 The evolution of social attractiveness and its role in shame, humiliation, guilt and therapy. British Fournal of Medical Psychology 70(2), 113-147.

1998 What is shame? Some core issues and controversies. In P. Gilbert \& B. Andrews (Eds.), Shame: Interpersonal behavior, psychopathology, and culture (pp. 3-38). New York: Oxford University Press.

2001 Evolution and social anxiety: The role of attraction, social competition, and social hierarchies. Psychiatric Clinics of North America. Special Issue: Social anxiety disorder 24(4), 723-751.

Gilbert, P. AND M.T. MaGuire

1998 Shame, status, and social roles: Psychobiology and evolution. In P. Gilbert \& B. Andrews (Eds.), Shame: Interpersonal behavior, psychopathology, and culture (pp. 99-125). New York: Oxford University Press.

Gilbert, P., J. Price and S. Allan

1995 Social comparison, social attractiveness and evolution: How might they be related? New Ideas in Psychology 13(2), 149-165.

GODDARD, G.

1996 The "social emotions" of Malay (Bahasa Melayu). Ethos 24(3), 426-464.

1997 Cultural values and "cultural scripts" of Malay (Bahasa Melayu). fournal of Pragmatics 27(2), 183-201.

GreenWALD, D.F. AND D.W. HARder

1998 Domains of shame: Evolutionary, cultural, and psychotherapeutic aspects. In P. Gilbert \& B. Andrews (Eds.), Shame: Interpersonal behavior, psychopathology, and culture (pp. 225-245). New York: Oxford University Press.

GREGOR, T.

1977 Mehinaku: The drama of daily life in a Brazilian Indian village. Chicago: University of Chicago Press.

HeIDER, K.G.

1991 Landscapes of emotion: Mapping three cultures of emotion in Indonesia. New York: Cambridge University Press.

Henderson, L.

2002 Fearfulness predicts self-blame and shame in shyness. Personality \& Individual Differences 32(1), 79-93. 
Henrich, J. And F.J. GIL-White

2001 The evolution of prestige: Freely conferred deference as a mechanism for enhancing the benefits of cultural transmission. Evolution \& Human Behavior 22(3), $\underline{165-196 .}$

Heyes, C.M.

1998 Theory of mind in nonhuman primates. Behavioral \& Brain Sciences 21(1), 101134.

Hofstede, G.H.

1991 Cultures and organizations: Software of the mind. New York: McGraw-Hill.

Hutchinson, S.E.

1996 Nuer dilemmas: Coping with money, war, and the state. Berkeley: University of California Press.

\section{JOHNSTON, V.S.}

1999 Why we feel: The science of human emotions. Reading, Mass.: Perseus Books.

Kaplan, H., K. Hill, J. Lancaster and A.M. Hurtado

2000 A theory of human life history evolution: Diet, intelligence, and longevity. Evolutionary Anthropology 9(4), 156-185.

KAREN, R.

1992 Shame. The Atlantic Monthly, 40-70.

KEELER, W.

1983 Shame and stage fright in Java. Ethos 11(3), 152-165.

KELLY, R.L.

1995 The foraging spectrum: Diversity in hunter-gatherer lifeways. Washington: Smithsonian Institution Press.

KELTNER, D.

1995 Signs of appeasement: Evidence for the distinct displays of embarrassment, amusement, and shame. Fournal of Personality \& Social Psychology 68(3), 441-454.

Keltner, D. And B.N. Buswell

1996 Evidence for the distinctness of embarrassment, shame, and guilt: A study of recalled antecedents and facial expressions of emotion. Cognition \& Emotion 10(2), 155-171.

1997 Embarrassment: Its distinct form and appeasement functions. Psychological Bulletin 122(3), 250-270.

Keltner, D. AND L. Harker

1998 The forms and functions of the nonverbal signal of shame. In P. Gilbert \& B. Andrews (Eds.), Shame: Interpersonal behavior, psychopathology, and culture (pp. 78-98). New York: Oxford University Press.

Keltner, D., R.C. Young and B.N. Buswell

1997 Appeasement in human emotion, social practice, and personality. Aggressive Behavior. Special Issue: Appeasement and reconciliation 23(5), 359-374.

\section{Kennedy, J.G.}

1978 Tarahumara of the Sierra Madre: Beer, ecology, and social organization. Arlington Heights, Ill.: AHM Pub. Corp. 
Kitayama, S., H.R. Markus and H. Matsumoto

1995 Culture, self, and emotion: A cultural perspective on "self-conscious" emotions. In J.P. Tangney \& K.W. Fischer (Eds.), Self-conscious emotions: The psychology of shame, guilt, embarrassment, and pride (pp. 439-464). New York: Guilford Press.

LAMBREGHT, F.

1932 The Mayawyaw ritual. Washington, D.C.: Catholic Anthropological Conference.

LAZARUS, R.S.

1991 Emotion and adaptation. New York: Oxford University Press.

LEARY, M.R., J.L. LANDEL AND K.M. PATTON

1996 The motivated expression of embarassment following a self-presentational predicament. Fournal of Personality 64(3), 619-636.

LEARY, M.R. AND S. MEADOWS

1991 Predictors, elicitors, and concomitants of social blushing. Zournal of Personality \& Social Psychology 60(2), 254-262.

LEBRA, T.S.

1983 Shame and guilt: A psychocultural view of the Japanese self. Ethos 11(3), 192209.

LEVY, R.I.

1973 Tahitians: Mind and experience in the Society Islands. Chicago: University of Chicago Press.

LEWIS, H.B.

1971 Shame and guilt in neurosis. New York: International Universities Press.

1987 The role of shame in symptom formation. Hillsdale, N.J.: L. Erlbaum Associates.

LEWIS, M.

1995 Embarrassment: The emotion of self-exposure and evaluation. In J.P. Tangney \& K.W. Fischer (Eds.), Self-conscious emotions: The psychology of shame, guilt, embarrassment, and pride (pp. 198-218). New York: Guilford Press.

Lindsay-Hartz, J., J. DE Rivera and M.F. Mascolo

1995 Differentiating guilt and shame and their effects on motivation. In J.P. Tangney \& K.W. Fischer (Eds.), Self-conscious emotions: The psychology of shame, guilt, embarrassment, and pride (pp. 274-300). New York: Guilford Press.

LuTz, C.

1988 Unnatural emotions: Everyday sentiments on a Micronesian atoll $\&$ their challenge to Western theory. Chicago: University of Chicago Press.

Lutz, C. AND G.M. White

1986 The anthropology of emotions. Annual Review of Anthropology 15, 405-436.

\section{Mascolo, M.F. AND K.W. Fischer}

1995 Developmental transformations in appraisals for pride, shame, and guilt. In J.P. Tangney \& K.W. Fischer (Eds.), Self-conscious emotions: The psychology of shame, guilt, embarrassment, and pride (pp. 64-113). New York: Guilford Press.

MAXWELL, K.B.

1983 Bemba myth and ritual: The impact of literacy on an oral culture. New York: P. Lang. 


\section{MaElreath, R., R. Boyd and P.J. Richerson}

2003 Shared norms can lead to the evolution of ethnic markers. Current Anthropology $\underline{44(1): 122-129 .}$

MEAD, M.

1937 Cooperation and competition among primitive peoples (1st ed.). New York: McGraw-Hill Book Company.

\section{Menon, U. And R.A. Shweder}

1994 Kali's tongue: Cultural psychology and the power of shame in Orissa, India. In S. Kitayama \& H.R. Markus (Eds.), Emotion and culture: Empirical studies of mutual influence (pp. 241-282). Washington, DC: American Psychological Association.

MERRILL, W.L.

1988 Rarámuri souls: Knowledge and social process in northern Mexico. Washington, D.C.: Smithsonian Institution Press.

Messenger, J.C.

1971 Sex and repression in an Irish folk community. In D.S. Marshall \& R.C. Suggs (Eds.), Human sexual behavior (pp. 3-37). New York: Basic Books.

Mikulincer, M. AND V. Florian

1997 A cognitive-relational approach to emotions - the appraisal and coping components of sadness, shame, guilt, jealousy, and disgust. Imagination, Cognition $\mathbb{E}^{2}$ Personality 16(3), 263-279.

MiYake, K. AND K. YAMAZAKI

1995 Self-conscious emotions, child rearing, and child psychopathology in Japanese culture. In J.P. Tangney \& K.W. Fischer (Eds.), Self-conscious emotions: The psychology of shame, guilt, embarrassment, and pride (pp. 488-504). New York: Guilford.

Moore, C.C., A.K. Romney, T.-L. Hsia and C.D. Rusch

1999 The universality of the semantic structure of emotion terms: Methods for the study of inter- and intra-cultural variability. American Anthropologist 101(3), 529546.

Mosher, D.L. AND B.B. White

1981 On differentiating shame and shyness. Motivation \& Emotion 5(1), 61-74.

MULDER, N.

1996 Inside Thai society: Interpretations of everyday life (5th ed.). Amsterdam: Pepin Press.

MYERS, F.R.

1979 Emotions and the self: A theory of personhood and political order among Pintupi Aborigines. Ethos 7(4), 343-370.

NASH, J.C.

1970 In the eyes of the ancestors: Belief and behavior in a Maya community. New Haven: Yale University Press.

Nathanson, D.L.

1992 Shame and pride: Affect, sex, and the birth of the self (1st ed.). New York: Norton.

NESSE, R.M.

1990 Evolutionary explanations of emotions. Human Nature 1(3), 261-289. 
OBEYESEKERE, G.

1981 Medusa's hair: An essay on personal symbols and religious experience. Chicago: University of Chicago Press.

Öehman, A. And S. Mineka

2001 Fears, phobias, and preparedness: Toward an evolved module of fear and fear learning. Psychological Review 108(3), 483-522.

Olthof, T., A. Schouten, H. Kuiper, H. Stegge And A. Jennekens-

SCHINKEL

2000 Shame and guilt in children: Differential situational antecedents and experiential

PARISH, S.M. correlates. British 7ournal of Developmental Psychology 18(Pt 1), 51-64.

1991 The sacred mind: Newar cultural representations of mental life and the production of moral consciousness. Ethos 19(3), 313-351.

Piers, G. AND M.B. Singer

1953 Shame and guilt: A psychoanalytic and a cultural study. Springfield, Ill.: Thomas.

Povinelli, D.J. and J.M. Bering

2002 The mentality of apes revisited. Current Directions in Psychological Science 11(4), 115119.

RICHARDS, A.I.

1956 Chisungu: A girls' initiation ceremony among the Bemba of Northern Rhodesia. London: Faber and Faber.

Rosaldo, M.Z.

1983 The shame of headhunters and the autonomy of the self. Ethos 11(3), 135-151.

1984 Toward an anthropology of self and feeling. In R.A. Schweder \& R.A. LeVine (Eds.), Culture theory: Essays on mind, self, and emotion (pp. 137-157). New York: Cambridge University Press.

ROZIN, P.

1999 Preadaptation and the puzzles and properties of pleasure. In D. Kahneman \&

E. Diener (Eds.), Well-being: The foundations of hedonic psychology (pp. 109-133). New

York, NY: Russell Sage Foundation.

2003 Five potential principles for understanding cultural differences in relation to individual differences. Fournal of Research in Personality 37(4), 273-283.

Rozin, P., J. Haidt, C. MaCauley And S. Imada

1997 Disgust: Preadaptation and the cultural evolution of a food-based emotion. In H. MacBeth (Ed.), Food preferences and taste (pp. 65-82). Providence, RI: Berghahn Books.

Russell, J.A.

1991 Culture and the categorization of emotions. Psychological Bulletin 110(3), 426-450.

Sabini, J., B. Garvey and A.L. Hall

2001 Shame and embarrassment revisited. Personality \& Social Psychology Bulletin 27(1), 104-117.

SABINI, J. AND M. SILVER

1997 In defense of shame: Shame in the context of guilt and embarrassment. Zournal for the Theory of Social Behaviour 27(1), 1-15. 
SACHDEV, P.S.

1990 Whakama: Culturally determined behaviour in the New Zealand Maori. Psychological Medicine 20(2), 433-444.

SCHEFF, T.J.

1988 Shame and conformity: The deference-emotion system. American Sociological Review 53(3), 395-406.

\section{SCHERER, K.R.}

1997 Profiles of emotion-antecedent appraisal: Testing theoretical predictions across cultures. Cognition E Emotion 11(2), 113-150.

SCHERER, K.R. AND H.G. WALlbotT

1994 Evidence for universality and cultural variation of differential emotion response patterning. Fournal of Personality E Social Psychology 66(2), 310-328.

SCHIMMACK, U. AND R. REISENZEIN

1997 Cognitive processes involved in similarity judgments of emotions. Zournal of Personality \& Social Psychology 73(4), 645-661.

SCHOECK, H.

1969 Envy: A theory of social behaviour (M. Glenny \& B. Ross, Trans.). New York: Harcourt Brace \& World.

SCHORE, A.N.

1998 Early shame experiences and infant brain development. In P. Gilbert \& B. Andrews (Eds.), Shame: Interpersonal behavior, psychopathology, and culture (pp. 57-77). New York: Oxford University Press.

SHARP, L. AND L.M. HANKS

1978 Bang Chan: Social history of a rural community in Thailand. Ithaca: Cornell University Press.

Shaver, P., J. Schwartz, D. Kirson and C. O'Connor

1987 Emotion knowledge: Further exploration of a prototype approach. Zournal of Personality \&5 Social Psychology 52(6), 1061-1086.

Shaver, P.R., U. Murdaya And R.C. Fraley

2001 Structure of the Indonesian emotion lexicon. Asian Fournal of Social Psychology 4(3), 201-224.

Shaver, P.R., S. WU AND J.C. Schwartz

1992 Cross-cultural similarities and differences in emotion and its representation. In M.S. Clark (Ed.), Emotion. Review of personality and social psychology, No. 13 (pp. 175-212). Thousand Oaks, Calif.: Sage Publications, Inc.

SimMONS, O.G.

1960 Ambivalence and the learning of drinking behavior in a Peruvian community. American Anthropologist 62, 1018-1027.

SMITH, R.H.

2000 Assimilative and contrastive emotional reactions to upward and downward social comparisons. In J. Suls \& L. Wheeler (Eds.), Handbook of social comparison: Theory and research (pp. 173-200). New York: Kluwer Academic/Plenum Publishers. 
Smith, R.H., J.M. Webster, W.G. Parrott and H.L. Eyre

2002 The role of public exposure in moral and nonmoral shame and guilt. fournal of Personality EO Social Psychology 83(1), 138-159.

SPIRO, M.E.

1996 Narcissus in Asia. Ethos 24(1), 165-191.

Strathern, A.

1977 Why is shame on the skin? In J. Blacking (Ed.), The anthropology of the body (pp. 99-110). New York: Academic Press.

Sutlive, V.H.

1972 From longhouse to pasar: Urbanization in Sarawak, East Malaysia. Ph.D. dissertation, Anthropology, University of Pittsburgh.

SWARTZ, M.J.

1991 The way the world is: Cultural processes and social relations among the Mombasa Swahili. Berkeley: University of California Press.

SWIFT, M.G.

1965 Malay peasant society in Felebu. New York: Humanities Press.

TANGNEY, J.P.

1992 Situational determinants of shame and guilt in young adulthood. Personality \& Social Psychology Bulletin 18(2), 199-206.

1995 Shame and guilt in interpersonal relationships. In J.P. Tangney \& K.W. Fischer (Eds.), Self-conscious emotions: The psychology of shame, guilt, embarrassment, and pride (pp. 114-139). New York: Guilford Press.

1998 How does guilt differ from shame? In J. Bybee (Ed.), Guilt and children (pp. 1-17). San Diego, Calif.: Academic Press, Inc.

1999 The self-conscious emotions: Shame, guilt, embarrassment and pride. In T. Dalgleish \& M.J. Power (Eds.), Handbook of cognition and emotion (pp. 541-568). Chichester, England: John Wiley \& Sons Ltd.

TAngney, J.P. And R.L. DEARING

2002 Shame and guilt. New York: The Guilford Press.

Tangney, J.P., R.S. Miller, L. Flicker and D.H. Barlow

1996 Are shame, guilt, and embarrassment distinct emotions? Zournal of Personality \& Social Psychology 70(6), 1256-1269.

Tinbergen, N.

1963 On aims and methods of ethology. Zeitschrift für Tierpsychologie 20(4), 410-433.

TOMKINS, S.S.

1987 Shame. In D.L. Nathanson \& et al. (Eds.), The many faces of shame (pp. 133-161). New York: Guilford Press.

TONKInson, R.

1978 The Mardudjara aborigines: Living the dream in Australia's desert. New York: Holt Rinehart and Winston.

URDANG, L.

1992 The Oxford thesaurus: American edition. New York: Oxford University Press. 
VAN BEEK, W.E.A.

1994 The innocent sorcerer: Coping with evil in two African societies (Kapsiki \& Dogon). London: J. Currey.

WALLBOTT, H.G.

1998 Bodily expression of emotion. European fournal of Social Psychology 28(6), 879-896. WallbotT, H.G. AND K.R. SchereR

1995 Cultural determinants in experiencing shame and guilt. In J.P. Tangney \& K.W. Fischer (Eds.), Self-conscious emotions: The psychology of shame, guilt, embarrassment, and pride (pp. 465-487). New York: Guilford Press.

WEISFELD, G.E.

1999 Darwinian analysis of the emotion of pride/shame. In J.M.G. v.d. Dennen \& D. Smillie \& et al. (Eds.), The Darwinian heritage and sociobiology (pp. 319-333). Westport, Conn.: Praeger Publishers/Greenwood Publishing Group, Inc.

1997 Discrete emotions theory with specific reference to pride and shame. In N.L. Segal \& G.E. Weisfeld \& et al. (Eds.), Uniting psychology and biology: Integrative perspectives on human development (pp. 419-443). Washington, DC: American Psychological Association.

Wicker, F.W., G.C. Payne and R.D. Morgan

1983 Participant descriptions of guilt and shame. Motivation E् Emotion 7(1), 25-39. WiERZBickA, A.

1986 Human emotions: Universal or culture-specific? American Anthropologist 88(3), 584594.

1992 Semantics, culture, and cognition: Universal human concepts in culture-specific configurations. New York: Oxford University Press.

WIKAN, U.

1980 Life among the poor in Cairo. London: Tavistock Publications.

WOLF, M.

1972 Women and the family in rural Taiwan. Stanford, Calif.: Stanford University Press. YAnG, S. AND P.C. Rosenblatt

2001 Shame in Korean families. Zournal of Comparative Family Studies 32(3), 361-375.

ZAHN-WAXLER, C. AND J. ROBINSON

1995 Empathy and guilt: Early origins of feelings of responsibility. In J.P. Tangney \& K.W. Fischer (Eds.), Self-conscious emotions: The psychology of shame, guilt, embarrassment, and pride (pp. 143-173). New York: Guilford Press. 